\title{
Exsolved Volatiles in Magma Reservoirs
}

4

\author{
Marie Edmonds ${ }^{1 *}$ and Andrew W. Woods ${ }^{1,2}$
}

1 Earth Sciences Department, University of Cambridge, Downing Street, Cambridge CB2 3EQ, UK 2 BP Institute, Bullard Laboratories, Madingley Rd, Cambridge CB3 0EZ, UK

*Corresponding author, marie.edmonds@esc.cam.ac.uk

1. Introduction

2. Achieving volatile saturation in magmas

2.1. Volatiles in natural magmatic systems

2.2. Sulfur partitioning into the exsolved volatile phase

3. Consequences of exsolved volatiles in magma reservoirs for rheology and dynamics 3.1. Magma compressibility

3.2. Pressure increase during second boiling

3.3. Effect of compressibility on the mass of magma erupted

4. The role of the exsolved volatile phase in magma mixing and mingling 4.1. Magma mixing and overturn, driven by vesiculation of the lower magma layer 4.2. Vesiculation of underplating magmas and formation of mafic enclaves

5. Exsolved volatile phase generation and transport through crystal-rich magma bodies

\subsection{Transport of an exsolved volatile phase in crystal-rich magma}

5.2. Implications of our new understanding of the transport of the exsolved volatile phase through crystalline magmas for ore deposits

6. Summary and problems for the future

9

0

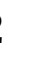




\section{Abstract}

We review our understanding of the exsolved volatile phase co-existing with magmas during preeruptive storage at the pressures and temperatures corresponding to crustal magma reservoirs. We explore the consequences and implications of such a volatile phase for magma and ore body petrogenesis and the fluid dynamics of magma reservoirs. We outline the geochemical constraints on the size and composition of the exsolved volatile phase that may co-exist with magmas in the crust. We distinguish between decompression-driven and crystallization-driven exsolution, and describe the implications of the volatiles for the dynamics of the magma reservoir, using key natural examples and case studies. We discuss eruptions triggered by second boiling, and the various regimes of magma mixing and magma overturn that may be induced by second boiling in a layered reservoir. We also explore the control of the volatile content of the magma on the mass erupted during an eruption episode, and compare our models to eruption datasets. We then turn to the mechanisms for magma-volatile separation, noting that in crystal-poor melts convective separation of exsolved volatiles may dominate while in crystal-rich melts, volatiles may generate channels or permeable-flow pathways through the crystal mush, thereby separating from the parent magma. We discuss the implications of the accumulation of the exsolved volatile phase at the roof zones of crystal-rich reservoirs for the large gas emissions observed during explosive eruptions, and for the development of metal-rich porphyry deposits.

\section{Introduction}

55 Magmas close to the surface of Earth, stored within crustal reservoirs, contain exsolved volatiles.

56 This exsolved volatile phase is made up of water and carbon dioxide primarily, but also significant amounts of sulfur and halogen gases, and trace constituents such as volatile metals (Gerlach, 1980; Symonds et al., 1994). These volatiles are dominantly sourced from the mantle,

59 but may also also be assimilated from crustal rocks and fluids (Mason et al., 2017) and are 60 enriched in silicate melts as they cool and fractionate. Typically, basaltic melts leave the mantle 61 carrying 0.1-4 wt\% $\mathrm{H}_{2} \mathrm{O}$ and $<2 \mathrm{wt} \% \mathrm{CO}_{2}$, depending on tectonic setting (Blundy et al., 2010; 62 Plank et al., 2013; Wallace, 2005), which increases due to fractionation prior to volatile saturation, reaching several $\mathrm{wt} \% \mathrm{H}_{2} \mathrm{O}$ for magmas in arc settings (Plank et al., 2013; Sisson and

64 Layne, 1993). These volatile species have a propensity to exsolve or partition into a low density exsolved volatile phase at crustal pressures, which may be a supercritical fluid at high pressures, and a vapour phase at low pressures. 
Despite only being a minor constituent of magmas, exsolved volatiles have enormous importance for a myriad of magma reservoir processes. An exsolved volatile phase lowers the bulk density and increases the buoyancy of magmas (Anderson, 1995), influences phase equilibria (Ghiorso and Gualda, 2015; Moore and Carmichael, 1998), as well driving convection (Cardoso and Woods, 1999; Longo et al., 2006) and promoting magma mingling and mixing through overturn (Huppert et al., 1982; Ruprecht et al., 2008). Recent work has shown that the exsolved volatile phase may be mobile in crystal-rich magma (Barth et al., in review; Oppenheimer et al., 2015; Parmigiani et al., 2016), leading to accumulation in the roof zones of magma reservoirs, which may play a role in triggering eruptions, activating hydrothermal systems through volatile injection (Chiodini et al., 2012) and in the generation of porphyries hosting economic concentrations of metals (Guo and Audétat, 2017; Huber et al., 2012).

Important new advances in observing and modeling magma reservoirs and their volatile systematics have prompted this review. Our understanding of the form and organisation of crustal magma reservoirs has evolved in recent years, towards a picture of trans-crustal, mushdominated, heterogeneous magma reservoirs which may be long-lived relative to inter-eruption timescales (Cashman et al., 2017; Cooper and Kent, 2014). Petrological evidence, from melt inclusion and pyroxene barometry (Edmonds et al., 2016; Hartley et al., 2014; Longpré et al., 2017; Métrich and Wallace, 2008; Neave and Putirka, 2017) suggests that magmas may be stored over a wide depth interval and that the magmas typically carry crystal cargos that record complex mixing and mingling histories (Cashman and Blundy, 2013; Cooper and Kent, 2014; Costa et al., 2013; Neave et al., 2013), suggesting repeated recharge and mixing of localised melts and mushes. Geophysical surveys of the crust show that melt-dominated magma bodies do not generally exist; instead it is envisaged that melts are disseminated in mushes or in closely-spaced sill-like bodies (Cordell et al., 2018; Kiser et al., 2016; Pritchard and Gregg, 2016).

94 Large fluxes of deep-derived sulfur-rich gas from long-lived eruptions such as Soufrière Hills 95 Volcano (Montserrat) (Christopher et al., 2015; Edmonds et al., 2010; Edmonds et al., 2001) and Bagana Volcano (Papua New Guinea) (Kilbride et al., 2018), which continue during prolonged eruptive pauses indicate that permeable, outgassing pathways through crystal-rich magma may be maintained from depth, perhaps tapping zones where an exsolved volatile phase accumulated

99 near the topmost regions of the magma reservoir system over multiple eruption timescales 100 (Christopher et al., 2015), with the system being recharged from time to time with heat and 101 volatiles by underplating mafic magmas (Bachmann and Bergantz, 2006; Murphy et al., 2000; 
Plail et al., 2014). The accumulation of an exsolved volatile phase in the roof zone of such a protracted reservoir may play a critical role in triggering and sustaining eruption. Observations of “excess sulfur" using space-borne satellites (Carn et al., 2016; Wallace, 2001) may be direct evidence of such deep accumulations of exsolved volatiles. Large volcanic "outgassing events" which may be observed using strain measurements (Hautmann et al., 2014), may relieve reservoir pressure and prevent magmatic eruptions. Accumulation of an exsolved volatile phase may also have important implications for the interpretation of ground displacements at the surface through the formation of a highly compressible region of the magma reservoir (McCormick Kilbride et al., 2016; Rivalta and Segall, 2008), which may buffer volume changes and suppress ground deformation.

This review will be concerned with both the geochemistry and physical dynamics of the exsolved volatile phase in the crust prior to eruption. We bring together geochemical and physical perspectives to review the state of the art in our understanding of the role and behaviour of volatiles in magma reservoirs and during magma ascent and eruption. We provide a synopsis of recent progress in this area in the key areas of observation, modeling and experiment and highlight outstanding, critical problems that remain to be solved.

\section{Achieving volatile saturation in magmas}

Magmas exsolve water and carbon dioxide as they rise through the crust, cool and crystallise. Owing to the relationship between volatile solubility and pressure (Dixon et al., 1995; Moore et al., 1998a; Newman and Lowenstern, 2002; Pan et al., 1991; Stolper and Holloway, 1988), melts can reach saturation with respect to an exsolved volatile phase during decompression (termed "first boiling") or during isobaric cooling and crystallisation (of volatile-poor crystals) in a magma storage area ("second boiling") (figure 1A and B), leading to the formation of a exsolved magmatic volatile phase (MVP) (Candela, 1997). A magma is said to be volatile-saturated when an exsolved volatile phase (which may be a supercritical fluid at high pressures, or a vapour at low pressures) is present and in equilibrium with the melt. Volatile exsolution occurs when the sum of the vapour pressures of the components of a liquid, $\sum\left(P_{i}^{\text {vapour }}\right)$, is equal to the load pressure (Candela, 1997). Volatile exsolution into bubbles will occur when either the load pressure is reduced, for example during decompression or removal of lithostatic load, "first boiling”, or $\sum\left(P_{i}^{\text {vapour }}\right)$ is increased, for example during crystallisation, "second boiling". 
135 Exsolution of water from silicate melt during decompression-induced degassing, or first boiling, 136 results in a lowering of the solidus, owing to a decrease in the entropy of mixing caused by the 137 loss of water from the melt. Decompression of magma is therefore usually accompanied by 138 extensive degassing-induced crystallisation (Cashman and Blundy, 2000; Cashman, 2004), which 139 has the effect of promoting further volatile exsolution and increasing the bulk viscosity of the 140 magma (Dingwell et al., 1996). These processes are first order controls on eruption style and the 141 onset of fragmentation (Blundy and Cashman, 2005; Dingwell, 1996; Melnik and Sparks, 2002) 142 (see later). Second boiling takes place in magma storage areas in the crust, where magmas cool 143 beneath their solidus temperatures and crystallise. If the fractionating assemblage is dominantly 144 anhydrous then as the liquid fraction decreases, the vapour pressure of the volatile components 145 increases, driving exsolution of volatiles (figure 1B). As magmas rise through the crust, the 146 balance between first and second boiling changes. As magma ascent slows, volatile exsolution 147 may be driven dominantly by cooling and crystallisation; whereas rapid rise of magma through 148 dykes to the surface will experience dominantly first boiling vesiculation and expansion. For the 149 case of large, complex magma reservoirs which evolve over long timescales $\left(10^{4}-10^{5} \mathrm{yr}\right)$ (Cooper 150 and Kent, 2014; Hawkesworth et al., 2000) the production of an exsolved volatile phase may 151 occur sporadically, with magma recharge events, superimposed on a background of slower 152 exsolved volatile production driven by cooling and crystallisation.

154 The composition of the evolving exsolved magmatic volatile phase will depend on the initial 155 volatile content of the magma, the pressure, temperature, melt composition and oxidation state. 156 There have been many recent formulations of empirical (Moore et al., 1998b) and 157 thermodynamic (Burgisser et al., 2015; Dixon and Stolper, 1995; Moretti et al., 2003; Papale, 158 1999; Witham et al., 2012) models to describe the chemical evolution of melt and exsolved 159 volatile phase in equilibrium during transit through the crust (figure 2). The thermodynamic 160 models are calibrated by experimental data on $\mathrm{H}_{2} \mathrm{O}$ and $\mathrm{CO}_{2}$ solubility and the partitioning of 161 sulfur between the aqueous exsolved volatile phase and silicate melt at a range of conditions.

162 Figure 2 illustrates the effect of $\mathrm{CO}_{2}$ on the composition and pressure at which volatile-saturation 163 occurs (Candela, 1997). One melt with $400 \mathrm{ppm} \mathrm{CO}_{2}$ and around $2 \mathrm{wt} \% \mathrm{H}_{2} \mathrm{O}$ crystallises at a 164 constant pressure of $200 \mathrm{MPa}$. Initially it is 'vapor'-undersaturated (here 'vapor' refers to the 165 exsolved volatile phase), but reaches vapor-saturation after around 50\% crystallization (red dot in 166 figure 2). At this stage the concentrations of $\mathrm{H}_{2} \mathrm{O}$ and $\mathrm{CO}_{2}$ have approximately doubled and $167 \sum\left(P_{i}^{\text {vapour }}\right)$ is $200 \mathrm{MPa}$, and the partial pressures of $\mathrm{H}_{2} \mathrm{O}$ and $\mathrm{CO}_{2}$ are both $\sim 100 \mathrm{MPa}$ and 168 therefore the molar proportions of $\mathrm{CO}_{2}$ and $\mathrm{H}_{2} \mathrm{O}$ in the co-existing exsolved volatile phase are 
169 approximately equal. Further vapor-saturated crystallization will cause the melt to evolve along 170 the $200 \mathrm{MPa}$ isobar, towards more $\mathrm{H}_{2} \mathrm{O}$-rich melt compositions. If no $\mathrm{CO}_{2}$ were present (figure 2, 171 bottom orange dot), then $64 \%$ crystallization is required before vapor-saturation occurs. Figure 3 172 shows the relationship between the melt $\mathrm{H}_{2} \mathrm{O}$ content, the mass of the exsolved volatile phase and 173 the degree of crystallization at $200 \mathrm{MPa}$ for a range of initial water contents. After $50 \%$ 174 crystallization, by which time basalt has become basaltic andesite, $1-5 \mathrm{wt} \%$ exsolved volatiles is 175 likely to co-exist with the melt. This is a minimum estimate; if $\mathrm{CO}_{2}$ is present this fraction will be 176 higher. Many authors have suggested that magmas may experience ' $\mathrm{CO}_{2}$-flushing' which will 177 tend to drive the melt towards higher $\mathrm{CO}_{2}$ concentrations (from right to left along an isobar in 178 figure 2) (Caricchi et al., 2018).

\subsection{Volatiles in natural magmatic systems}

181 Perhaps our best source of information regarding the pre-eruptive volatile concentrations of 182 silicate melts are given by the volatile contents of melt inclusions (Kent, 2008; Lowenstern, 183 1995; Métrich and Wallace, 2008; Sides et al., 2014b). We now understand, however, that many 184 processes modify the concentrations of volatiles in melt inclusions post-entrapment, such as sequestration of $\mathrm{CO}_{2}$ into a shrinkage bubble (Esposito et al., 2014; Moore et al., 2015; Wallace

186 et al., 2015), perhaps driven by cooling and post-entrapment crystallization (Sides et al., 2014a; 187 Steele-Macinnis et al., 2011), diffusive loss (Bucholz et al., 2013; Gaetani et al., 2012; Lloyd et 188 al., 2013) or gain (Hartley et al., 2015) of hydrogen. A dataset of melt inclusion $\mathrm{CO}_{2}$ and $\mathrm{H}_{2} \mathrm{O}$ data, for A) a range of basalts in hotspot and arc settings and B) andesites, dacites and rhyolites in arc and rift settings, is shown in Figure 4. The data for both the mafic magmas and the more evolved magmas show an array in volatile concentrations, caused by a combination of factors

193 (Métrich and Wallace, 2008), mixing (Dixon et al., 1991) and volatile loss from the inclusions 194 (Gaetani et al., 2012; Maclennan, 2017). A degassing path is one whereby $\mathrm{CO}_{2}$ is lost at high 195 pressure, followed by $\mathrm{H}_{2} \mathrm{O}$ at low pressure (Dixon and Stolper, 1995). The dissolved volatile data for both basalts and rhyolites, in all tectonic settings, is consistent with volatile-saturation at pressures of up to $300 \mathrm{Mpa}$ or more in the crust, equivalent to 11-13 km depth. For ocean island magmas, the exsolved volatile phase at this depth is highly $\mathrm{CO}_{2}$-rich, owing to the much lower bulk $\mathrm{H}_{2} \mathrm{O}$ concentrations; in arcs, the deep exsolved volatile phase is more hydrous. If, as seems likely, the melt inclusion record is overprinted by shallow storage prior to eruption (due to $\mathrm{H}+$ loss by diffusion, see above), the deeper record may be routinely erased. 
205 Phase equilibria studies have been of value in reconstructing the pre-eruptive water contents of 206 arc basalts (Barclay et al., 1998; Sisson and Grove, 1993). In Mexico, phase assemblages in 207 erupted rocks are consistent with experimental assemblages under volatile-saturated conditions at 208 170-200 MPa (Moore and Carmichael, 1998), indicating that an aqueous fluid phase with a high 209 activity of $\mathrm{H}_{2} \mathrm{O}$ co-existed with magma prior to eruption. Plagioclase hygrometers (Lange et al., 210 2009; Putirka, 2005; Waters and Lange, 2015) allow estimates of the water content of basaltic 211 melts to be made: it has been suggested that An contents of plagioclase in arc basalts in Japan 212 indicate pre-eruptive basaltic water contents of 3-5 wt\% (Ushioda et al., 2014), which is 213 consistent with melt inclusion studies (Kuritani et al., 2014; Rose-Koga et al., 2014). These 214 basalts have potential to generate large amounts of an exsolved volatile phase upon evolution to 215 higher-silica magmas. Other mineral proxies may be useful to reconstruct melt volatile 216 concentrations. A recent study of hydrogen in the cores of orthopyroxenes erupted during 217 vulcanian activity at Soufrière Hills Volcano were used to suggest that melt $\mathrm{H}_{2} \mathrm{O}$ contents were 4$2189 \mathrm{wt} \%$ prior to eruption, implying volatile-saturated magma storage at depths of up to $\sim 12 \mathrm{~km}$ 219 prior to eruption (Edmonds et al., 2016). Anorthite-rich plagioclase in xenocrysts (derived from 220 disaggregated mushes), Al-rich melts and experimental phase equilibria were used to infer that 221 parental basaltic andesites beneath St Kitts (Lesser Antilles) are water-rich ( $>9 \mathrm{wt} \%$ ) and they 222 crystallise over a wide pressure range (1.5 to $6.0 \mathrm{kbar}$ ) (Melekhova et al., 2017).

223 Geochemical proxies might allow reconstruction of magmatic water budgets. It has been 224 recognised recently that high $\mathrm{Sr} / \mathrm{Y}$ ratios in magmas are linked to fertility in copper (Richards, 225 2011). High $\mathrm{Sr} / \mathrm{Y}$ ratios, for example in Tibetan post-collisional magmas, have been attributed to 226 high magmatic water contents of $>10 \mathrm{wt} \%$, acting to suppress plagioclase fractionation (and 227 hence Sr removal) during fractional crystallisation of hydrous basalt parent magma at depth 228 (Chiaradia et al., 2012; Lu et al., 2015). These magmas have been compared to others in 229 subduction zone settings: silicic high $\mathrm{Sr} / \mathrm{Y}$ andesites and dacites at Mount Shasta, a stratovolcano 230 in the southern Cascades, contain melt inclusions with $>10 \mathrm{wt} \% \mathrm{H}_{2} \mathrm{O}$ which crystallised at 0.8 231 GPa (Grove et al., 2002). Similar experimental phase equilibria were shown for the Pinatubo 232 dacite melt: in order to produce high $\mathrm{Sr} / \mathrm{Y}$ with a starting melt composition of $16.5 \mathrm{wt} \% \mathrm{Al}_{2} \mathrm{O}_{3}$ 233 requires a melt water content of $>10 \mathrm{wt} \%$ (Prouteau and Scaillet, 2003). The existence of 234 hydrous magmas deep in the crust lends support to the notion that magma reservoirs from the 235 mid-crust upward contain substantial fractions of exsolved water as supercritical fluid or low 236 density vapour at lower pressures. 
237 Plutonic rocks exposed at the surface, however, present only scant evidence of an exsolved 238 magmatic volatile phase, despite abundant petrological evidence of hydrous components in the 239 melt (the presence of amphibole or biotite, for example). Comb-layered quartz, with its high 240 concentrations of fluid-mobile trace elements, is found in shallow felsic intrusions associated 241 with ore bodies, and is proposed to precipitate at the wallrock-magma contact from exsolved

242 hydrous fluids at the apical regions of magma bodies (Lowenstern and Sinclair, 1996). Some 243 granite bodies and pegmatites contain miarolitic cavities made up of super-solidus minerals, 244 externally nucleated, projecting into a quasi-spherical void (Candela, 1997). These features are 245 accepted as good evidence for magmatic exsolved volatile phase saturation in plutonic igneous 246 rocks (Candela, 1997). The absence of miarolitic cavities in granites and other igneous rocks does 247 not preclude that the magma body was saturated with respect to an exsolved volatile phase; the 248 preservation of such features depends on the depth and water content of the magma, as well as 249 crystal size, and the permeability of the mush during solidification. Some of these factors will be 250 discussed further in section 5.

251 Overall the data from natural systems appear to show that magmas may be volatile-saturated 252 from depths of 9 to $12 \mathrm{~km}$ up to the surface in most magmatic systems, including hotspots, arcs 253 and continental rifts. There may be exceptions, however. A recent study using apatites to 254 reconstruct the volatile budget of Campi Flegrei suggested that phonolitic magma at $7 \mathrm{~km} \mathrm{depth}$ 255 was volatile-undersaturated; while that stored at $3 \mathrm{~km}$ was volatile-saturated (Stock et al., 2016). 256 In mid-ocean ridge and hotspot settings, basaltic melts typically contain little $\mathrm{H}_{2} \mathrm{O}(<1.0 \mathrm{wt} \%$ and 257 usually $<0.5 \mathrm{wt} \%$; figure 4); for these magmas, saturation in an exsolved fluid phase occurs in 258 the mid-crust but the fluid is initially very $\mathrm{CO}_{2}$-rich; water does not exsolve from the melt in 259 significant quantities until the magma is within a few hundred metres of the surface (Newman 260 and Lowenstern, 2002); or until after significant amounts of isobaric crystallization has taken 261 place.

\subsection{Sulfur partitioning into an exsolved volatile phase}

264 As well as the primary volatile species, $\mathrm{H}_{2} \mathrm{O}$ and $\mathrm{CO}_{2}$, sulfur is also present at bulk 265 concentrations of up to $0.5 \mathrm{wt} \%$ in arc magmas (Carroll and Rutherford, 1985; Jugo, 2009; 266 Metrich and Clocchiatti, 1996; Wallace and Edmonds, 2011). Sulfur has significance owing to its 267 ability to complex with metals in the magmatic exsolved volatile phase and transport them to 268 sites of ore deposits (Botcharnikov et al., 2010; Zajacz and Halter, 2009); but also because 269 "excess" sulfur emissions during large explosive volcanic eruptions may lead to tropospheric 270 cooling owing to the influence of sulfate aerosols on the radiation budget of Earth's atmosphere 
271 (Robock, 2000). It has long been observed that the mass of sulfur released, as observed using 272 satellite sensors, from intermediate, i.e. andesite, dacite, eruptions in arcs is far larger than can be 273 accounted for by the syn-eruptive degassing of melt, as deduced from the sulfur content of melt 274 inclusions (Wallace, 2001; Wallace and Gerlach, 1994). A solution to this conundrum emerged 275 after the 1984 El Chichon eruption, which released $7 \mathrm{Tg}$ sulfur into the atmosphere (Bluth et al., 276 1997). It was proposed that, prior to eruption, a large fraction of the sulfur existed in a pre277 eruptive exsolved volatile phase, rich in $\mathrm{H}_{2} \mathrm{~S}$ (Luhr et al., 1984). This hypothesis gained traction 278 with the observation of other large explosive eruptions (Wallace, 2001; Wallace and Gerlach, 279 1994; Westrich and Gerlach, 1992), as well as the experimental observations, which followed, 280 that sulfur partitions strongly into aqueous exsolved volatile phase at crustal pressures for water281 rich, relatively evolved magmas (Clémente et al., 2004; Keppler, 1999; Scaillet et al., 1998;

282 Scaillet and Pichavant, 2005; Zajacz et al., 2012).

284 The sulfur content of an exsolved volatile phase in a magma reservoir may be estimated using a thermodynamic approach using homogeneous equilibria in the $\mathrm{C}-\mathrm{O}-\mathrm{H}-\mathrm{S}$ system (Oppenheimer et al., 2011; Scaillet and Pichavant, 2003). An exsolved volatile phase that evolves in a magma reservoir prior to eruption is highly variable in sulfur content, dependent on $\mathrm{fO}_{2}$, magma composition and temperature. Furthermore, in order to make the computed composition of the exsolved volatile phase match with that observed at the surface, using satellite-based methods, which has been overprinted by decompression-induced degassing, at least $1 \mathrm{wt} \%$ and in some cases up to $5 \mathrm{wt} \%$ of an exsolved volatile phase must be present in the magma reservoir. A preeruptive volatile phase is not required, or much less is required, to explain volcanic gas composition and output from more mafic systems (Oppenheimer et al., 2011; Scaillet and Pichavant, 2003). Large amounts of exsolved volatiles co-existing with magmas at depth will buffer the $\mathrm{C} / \mathrm{S}$ ratio of volcanic gases observed at the surface.

The presence of a few wt $\%$ exsolved volatiles from thermodynamic calculations is consistent with studies of melt inclusion geochemistry and models of fractional crystallisation, which suggested that the magma reservoir that fed the Bishop Tuff was zoned with respect to exsolved volatiles, containing up to $6 \mathrm{wt} \%$ near the roof zone (Wallace et al., 1999). A recent study of the volcanic products of the Samalas eruption, Indonesia, which involved eruption of at least $40 \mathrm{~km}^{3}$ and has been unmasked as the source of the mysterious 1257 sulfate spike in the ice core records (Lavigne et al., 2013) suggests exsolved magmatic volatile contents of $>3 \mathrm{wt} \%$, based on melt inclusion systematics and fractionation modeling (Vidal et al., 2016). Sulfur partitioning into this 
water-rich exsolved volatile phase resulted in a syn-eruptive sulfur emission into the atmosphere of $79+/-6$ Tg (Vidal et al., 2016). Studies of long-lived eruptions with well-constrained records of magma and gas fluxes, combined with melt inclusion studies, have allowed independent estimates of the proportion of exsolved volatiles present in the magma reservoir. At Soufrière Hills (Montserrat) much of the sulfur exists in a pre-eruptive exsolved volatile phase prior to eruption, which may comprise to to $2-3 \mathrm{wt} \%$ of the magma at 150-200 MPa (Edmonds et al., 2014b).

\section{Consequences of exsolved volatiles in magma reservoirs for rheology and dynamics}

314 The presence and production of an exsolved volatile phase in crustal magma reservoirs can lead to a number of different effects on rheology, compressibility and on eruption duration and style, depending on a range of factors, including whether the magma reservoir is sealed or open to the atmosphere, the crystal content and viscosity of the melt, and on whether the magma reservoir is composed of a single magma body or multiple bodies of melt with different composition and gas content. We first describe the changes in magma rheology that might occur when second boiling occurs (figure 1) in a crystal-rich magma, generating an exsolved volatile phase, manifest as disseminated fluid bubbles. We then describe the change in the pressure and density of magma in a chamber resulting from the exsolution of volatiles, associated with second boiling, assuming the mixture of melt, bubbles and crystals remains well-mixed. We then consider the effects of the relative motion of the gas phase, melt and crystals, and consider the implications of this for the dynamics of the system, including the effects of magma mixing, and observations of large volumes of erupted gas (“excess sulfur"; see section 2.2).

\subsection{Magma Compressibility}

329 In a magma that contains dissolved volatiles, cooling and crystallisation will induce saturation in 330 an exsolved volatile phase (second boiling; as shown in figure 1). The exsolved volatile phase is 331 typically of lower density than the melt phase and this process therefore leads to an increase in 332 volume and hence pressure of the magma body as it deforms the surrounding crust. The effect of this increase in pressure may be to trigger an eruption (Blake, 1984; Tait et al., 1989) or the injection of magma to a higher level in the crust. The relation between the change in volume and the change in pressure during both the inflation and the deflation phases of the evolution of the system depends on the compressibility of the melt-volatile-crystal mixture (Huppert and Woods, 2002; Rivalta and Segall, 2008; Segall, 2013; Voight et al., 2010). With a volatile-saturated melt, the magma may be of order 10 times more compressible than a magma with no exsolved 
339 volatiles. As a result, there may be a much greater volume of magma erupted prior to the 340 relaxation of the reservoir pressure and closure of the conduit (Huppert and Woods, 2002; Woods 341 and Huppert, 2003). Although the detailed calculation of the compressibility depends on the 342 volatile solubility as a function of pressure and crystal content, it is useful to explore the 343 predictions of a simplified model using (1a) Henry's law, (1b) a relation between the crystal 344 content and temperature; (1c) a model of an elastic chamber with effective bulk rock 345 compressibility (the inverse of the bulk modulus) $\beta$; and (1d) an idealized model for the density 346 of the gas as given by the ideal gas law, which is approximately valid for shallower (upper 347 crustal) systems.

$n_{e}=n_{o}-s P$ if $n_{o}>s P$ and $n_{e}=0$ if $n_{o}<s P$

$$
1 / \rho=\left(n_{e} R T / P+\left(1-n_{e}\right) / \rho_{m}\right)
$$

352 where $n$ denotes volatile mass fraction, with subscript $e$ denoting exsolved volatiles and $o$ 353 denoting the total mass of volatiles per unit mass of original melt. $P$ is pressure and $s$ is a 354 solubility constant. $x$ denotes crystal fraction (excluding the volatile phase), $T$ temperature (in 355 Kelvin) and $V$ the chamber volume, while $R$ is the ideal gas constant. The bulk density of the magma-crystal-volatile mixture is denoted by $\rho$ while the bulk density of the melt-crystal mixture is $\rho_{m}$. Such a simplified model provides insight into the behaviour of the system and allows us to distinguish the different controlling effects on the evolution of the melt.

360 Combining these relations, we can calculate the compressibility (or the inverse of the bulk 361 modulus of the mixture) defined as

as a function of pressure. In figure 5a, we illustrate the compressibility for the cases of magma with three different volatile contents at different depths in the crust, which shows that the compressibility becomes much larger once the melt reaches shallow depths where there are exsolved volatiles. The compressibility of the melt evolves as the melt cools and crystallises 
during second boiling. In figure $\mathbf{5 b}$, we illustrate the compressibility of magma with bulk $\mathrm{H}_{2} \mathrm{O}$ contents of 3,4 and $6 \mathrm{wt} \%$ at a depth of $5 \mathrm{~km}$, with the compressibility shown as a function of the crystal content of the melt. Once the magma crystallises sufficiently such that the melt reaches saturation in an exsolved volatile phase, the magma compressibility increases by over an

371 order of magnitude.

373 Magma compressibility, caused by the presence of an exsolved magmatic volatile phase in the reservoir, has implications for the interpretation of volcano monitoring data and impacts the magnitude of ground displacements as well as the composition and flux of volcanic gases (Biggs and Pritchard, 2017; McCormick Kilbride et al., 2016). At Soufrière Hills Volcano, Montserrat for example, a gas-rich compressible magma (the 'magma sponge') was invoked to explain why surface displacements, measured by Global Positioning Satellite (GPS) receivers on the volcano's flanks, yielded a much smaller volume displacement than the actual volume erupted, for particular time periods within the eruption (1995-2011) (Voight et al., 2010). It has been observed that the volume change inferred from magma chambers feeding shallower dyke intrusions is often a factor of 4-5 lower than the volume increase observed in the dyke, which has been explained by a combination of decompression-driven degassing and consequent increase in magma compressibility, combined with the more compliant dyke geometry (Rivalta and Segall, 2008). A database of eruptions for which the change in volume of the chamber and the volume erupted were well-constrained by the complementary data sets obtained from satellite measurements of the volcano deformation and ground-based measurements of the mass erupted is summarized by (McCormick Kilbride et al., 2016). They find that the volumes are generally in the ratio 1-20, which indicates the presence of exsolved volatiles in the magma reservoir; however, it is worth noting that it is somewhat difficult to constrain the actual change in volume of the magma chamber without detailed information of the shape and depth of the chamber, which can lead to changes in the effective bulk compressibility $\beta$ by up to an order of magnitude (Anderson and Segall, 2011; Rivalta and Segall, 2008; Segall, 2013).

\subsection{Pressure increase during second boiling}

396 Second boiling during cooling and crystallization, generating a magmatic exsolved volatile phase, 397 can produce enough pressure in the magma reservoir to trigger eruption (Blake, 1984; Tait et al., 1989; Woods and Cardoso, 1997). As a simplified calculation, in a more viscous melt, the pressure increase through cooling and the associated crystallization and volatile exsolution can be expressed by the relation 
403 where the change in volume associated with the cooling and volatile expansion and exsolution is 404 accommodated by compression of the remaining magma-volatile mixture, with compressibility $405 \beta_{m}$, and the surrounding country rock with effective compressibility $\beta$.

407 The predictions of this model are shown in figure $\mathbf{5 c}$ in which we see that the change in pressure 408 per degree of cooling, relative to the critical overpressure to trigger an eruption, as a function of 409 the crystal content of the melt. In this model, the chamber is assumed to be closed, and cooling 410 leads to crystallisation, exsolution and deformation of the surrounding country rock. Here the 411 critical overpressure to drive an eruption, $P_{c}$, has been set to the value $10^{7} \mathrm{~Pa}$ (Blake, 1984; 412 Woods and Cardoso, 1997) for illustration. It is seen that once the magma is volatile-saturated, 413 the continued exsolution of volatiles with cooling leads to a significant expansion of the melt414 crystal-volatile mixture and a large associated increase in the pressure. In the calculations shown, 415 for magma with 3, 4 or $6 \mathrm{wt}^{\%} \mathrm{H}_{2} \mathrm{O}$, with cooling of the melt by an amount of order $10{ }^{\circ} \mathrm{C}$, the 416 pressure will increase up to about $10^{7} \mathrm{~Pa}$, leading to eruption. In contrast, if the melt is not 417 volatile-saturated, then the increase in pressure with cooling is only associated with either the 418 density change as melt precipitates crystals, or the bulk cooling of the melt, and these are much 419 smaller effects.

\subsection{Effect of compressibility on the mass of magma erupted}

422 If the critical pressure to trigger an eruption from a magma reservoir is $\Delta P_{c}$, where $\Delta \mathrm{P}_{\mathrm{c}}<<\mathrm{P}_{1}$, 423 (where $\mathrm{P}_{1}$ is the lithostatic pressure), then the volume increase in the magma reservoir to 424 accommodate this overpressure, relative to the lithostatic pressure, is given by $\Delta V=V \beta \Delta P_{c}$, 425 based on the response of the crust. On eruption, this overpressure is relieved. The mass of melt in 426 the chamber associated with the overpressure, $\Delta M$, is given by

$427 \Delta M=V \Delta \rho+\rho \Delta V=M\left(\beta+\beta_{m}\right) \Delta P_{C}$

428 and this also corresponds to the mass erupted to relieve the overpressure. The volume erupted, $429 \Delta V_{e}=\Delta M / \rho$, depends on the volume change of the chamber, $\Delta V$, according to the relation

$$
\Delta V_{e}=\left(\beta_{m} / \beta+1\right) \Delta V
$$


431 For a given fracture strength of the crust and hence a given change in volume of the chamber $\Delta V$

432 the volume erupted, $\Delta V_{e}$, increases with the volatile content of the magma, since the very large 433 compressibility of the exsolved volatile phase can accommodate large changes in volume for 434 relatively small changes in pressure. This leads to much larger erupted volumes for volatile-rich 435 magmas (Bower and Woods, 1998; Huppert and Woods, 2002).

437 If an eruption is modelled with a simple frictional law associated with the frictional resistance in 438 the conduit, $f L$, and the overpressure in the chamber, $\Delta P(t)$, which implicitly requires that the 439 volatiles separate from the melt (i.e. perfect open system degassing with no gas remaining in the 440 melt) as the magma ascends to the surface (Jaupart and Allègre, 1991; Menand and Phillips, 441 2007; Woods and Koyaguchi, 1994), then the mass flow rate is given by

443 Combining this relation with equation (3), it follows that the eruption rate will decay 444 exponentially with time according to the relation (Huppert and Woods, 2002)

$d M / d t=\Delta P_{C} \exp \left(-f L t / M\left(\beta+\beta_{m}\right)\right)$

446 assuming constant coefficients for the frictional resistance. Since typical fracture pressures are of 447 order $10^{6}-10^{7} \mathrm{~Pa}$ (Touloukian et al., 1989), while the bulk compressibility is typically of order $44810^{-8}-10^{-10} \mathrm{~Pa}^{-1}$ for volatile-saturated and unsaturated magma, the volume of melt which erupts in 449 such conduit or dyke-controlled eruptions may range from a few percent of the total volume of 450 the chamber to a fraction of a percent in volatile-poor magmas. Equation 7 illustrates that the 451 eruption duration increases with the compressibility of the magma, with the eruption duration $t$ 452 scaling as

$t=M\left(\beta+\beta_{m}\right) / f L$

454 and this is consistent with the increased mass erupted for a volatile-saturated magma. The eruption rate depends primarily on $\Delta P(t) / f L$ as indicated by equation 6.

456 This model of the overall long-term control on eruption evolution, although simplified, can be 457 compared with a number of historical eruption episodes for which the erupted volume has been 
measured as a function of time, including the eruptions of Soufrière, St Vincent (Huppert et al., 459 1982) and Paracutin, Mexico (Fries Jr, 1953), where the eruption rate seems to follow an 460 exponential decay law with time (figure 6a; after (Berkowitz and Woods, 2018 under review)). 461 However, there is growing evidence that in some some systems, there are multiple magma 462 reservoirs which can drive an eruption, and in particular, there is evidence that the eruption of 463 Eyjafyallojokull in 2010 involved mobilization of magma from three different levels in the crust, 464 in sequence, with a shallower magma reservoir being tapped, followed by an intermediate and 465 then a deep magma reservoir (Tarasewicz et al., 2012). This interpretation of multiple reservoirs 466 is also consistent with the eruption of Lonquimay (Moreno and Gardeweg, 1989) in which the 467 eruption rate showed a more complex evolution, with an initially rapid exponential decay during 468 the eruption of the first $50 \%$ of the magma, followed by a more gradual exponential decay during 469 the second phase of eruption (figure $\mathbf{6 b}$ ). This eruption rate trend perhaps indicates a two 470 reservoir system, both of comparable size, in which the shallow reservoir initially erupts and 471 decompresses. This is then followed by the onset of eruption from the deeper reservoir, driving 472 new magma into the shallow reservoir, and causing the eruption to persist until the two reservoirs 473 re-equilibrate. In this case, one can envisage a double reservoir model, with a rate constant for 474 flow from the shallow reservoir to the surface, and a second rate constant for the flow between 475 the deeper and shallower reservoir (Berkowitz and Woods, 2018 under review).

477 Other historical eruptions also suggest that the gradual decompression of a deep magma reservoir exerts a long term control on the eruption rate. For example, the 1980-1985 eruption of Mt St Helens involved a series of intermittent slow dome-building and short dome-explosion events 480 following the initial major eruption episode (Brantley and Myers, 2000). Analysis of reported 481 data on the eruption volume during this 5-6 year period suggests a slow exponential decay of the 482 time-averaged eruption rate (figure 6c). Although the actual eruption history was intermittent, 483 owing to the non-linear controls associated with the formation and failure of the dome (Barmin et 484 al., 2002; Melnik and Sparks, 1999), the long term build up of pressure in the dome, between 485 each event appears to have been controlled by the flux from a gradually waning deeper reservoir 486 (Berkowitz and Woods, 2018 under review). Indeed, by modelling the non-linear valve-like 487 dynamics of the conduit feeding the dome in terms of a small critical overpressure for failure and 488 eruption of a shallow reservoir, the control on the long-term behavior of the system can be 489 rationalised in terms of the decompression of a deep reservoir.

\section{The role of the exsolved volatile phase in magma mixing and mingling}


492 Exsolved volatiles play an important role in magma mixing and mingling in magma reservoirs

493 (Bachmann and Bergantz, 2006; Degruyter and Huber, 2014; Edmonds et al., 2010; Huber et al.,

494 2011; Huppert and Woods, 2002; Pallister et al., 1996; Phillips and Woods, 2002; Ruprecht and 495 Bachmann, 2010; Woods and Cowan, 2009). Magma intrusion has often been cited as a trigger 496 for eruption (Eichelberger, 1980; Martin et al., 2008; Pallister et al., 1992; Sparks et al., 1977), 497 and there is frequently petrological and geochemical evidence of magma mixing and /or heating 498 shortly before eruptions (Metrich et al., 1993; Murphy et al., 2000; Rae et al., 2016; Ruprecht et 499 al., 2012). Magma mingling may manifest as mafic inclusions and banded and streaked eruption 500 products (Coombs et al., 2000; Plail et al., 2018; Sparks et al., 1977; Steiner et al., 2012; Tepley 501 et al., 1999; Watts et al., 1999); and magma mixing as hybrid magmas, formed by the efficient 502 mixing of magmas prior to eruption (which may encompass the disaggregation and scavenging of 503 crystal phases), commonly displaying disequilibium textures and petrological features (Cassidy et 504 al., 2015; Sparks and Marshall, 1986; Wright and Fiske, 1971). In this section we explore some 505 general mechanisms, explored through analogue experiments and simple analytical models, by 506 which the exsolved volatile phase may play a role in such processes, whereby intruding magma 507 may interact with overlying magma, triggering mixing and eruption.

\subsection{Magma mixing and overturn, driven by vesiculation of underplating basalt}

510 If an intrusion of hot, relatively dense magma occurs below an existing body of cooled, evolved 511 melt, the new lower layer of magma may inflate through cooling, crystallisation and exsolution 512 of volatiles, but may remain dense relative to the overlying layer. It is possible, however, for this 513 underplating magma to drive the eruption of the overlying magma (Burgisser and Bergantz, 514 2011; Huppert et al., 1982; Martin et al., 2008; Murphy et al., 2000; Sparks et al., 1984). The 515 control on the erupted volume will be associated with the expansion of the volatiles in the 516 underplating melt body, even though it is the overlying magma which erupts. The mass of magma 517 erupted depends on the relative volume of the upper and lower layers of magma, since both will 518 expand as the chamber pressure falls. With the upper layer erupting, the volume erupted as the 519 pressure falls by anount $\Delta P$ is now given by

521 where $V_{L}+V_{u}=V$, the total magma reservoir volume. It follows that as the fractional volume 522 change of the new volatile-rich magma $\left(V_{L}\right)$ increases, the mass erupted also increases, even if 
523 this is the less dense, overlying, degassed magma $\left(V_{u}\right)$. This is because the mass erupted is 524 creating space for the expansion of the volatile-rich magma which is much more compressible 525 than the overlying magma.

527 The reduction in the density of the underplating body of magma, caused by cooling and 528 crystallization and associated exsolution of volatiles, may eventually cause this magma to 529 become less dense than the original magma in the reservoir. As a result, there may be an overturn 530 or mixing event, driven by degassing (Huppert et al., 1982; Ruprecht et al., 2008; Sparks et al., 531 1984; Woods and Cowan, 2009). If the new, initially dense intrusion is relatively thin and of low 532 viscosity compared to the original melt, then the plumes of this low viscosity melt will be thin 533 and may become stirred into the overlying melt, especially if that melt is convecting. This can 534 lead to formation of mafic inclusions or an intermingled melt (Phillips and Woods, 2002). In 535 contrast, with a deeper or more viscous underplating magma, there may be a more complete 536 overturn, with plumes of the underplating magma being larger and accumulating at the top of the 537 overlying magma. In this case, on eruption, the crystalline mafic magma may be the dominant 538 phase which issues from the system. The intermingling, or mixing, produced by pre-eruption 539 cooling and crystallization has been explored in a series of experiments in which an increasing 540 volume of bubbles were created by electrolysis in a layer of viscous saline solution overlain by a 541 less dense, viscous bubble-free solution (figure 7) (Woods and Cowan, 2009). The experiments 542 illustrate the important control of the viscosity contrast between the melts as well as the relative 543 depths of the magma layers on whether there is stirring and mixing or overturn.

545 It is also possible that, during an eruption, the reduction in the pressure in the magma chamber 546 can lead to a reversal in the relative density of the two magmas (Ruprecht et al., 2008; Woods 547 and Cowan, 2009). This may lead to a change in the composition of the erupting magma during 548 the eruption provided that the eruption is sufficiently long-lived for overturn to occur. This 549 mechanism may provide an explanation for the heterogeneous chemical and textural 550 characteristics of crystal cargoes erupted in hybrid magmas, which suggest complex magmatic 551 mixing histories (Davidson and Tepley, 1997; Ruprecht et al., 2008; Singer et al., 1995). With a typical density contrast of order $10-100 \mathrm{~kg} / \mathrm{m}^{3}$, magma of viscosity 100-1000 Pas and of depth $55310-100 \mathrm{~m}$, the time scale for overturn would be of order $10^{3}-10^{4} \mathrm{~s}$ and this requires the eruption to 554 persist for a time of order hours, as is the case in larger explosive eruptions. 
556 Woods and Cowan (2009) carried out a series of analogue experiments in which a volatile-rich layer of saline and viscous natrasol solution underlay a volatile poor layer of relatively fresh but viscous natrasol solution. The volatile phase was $\mathrm{CO}_{2}$ dissolved in tap water. As the pressure is reduced to pressures of order 0.01-0.1 of atmospheric pressure, the volatiles exsolve, and, in the

560 viscous solution, they form a bubble-rich layer. In the experiment, the upper solution was 561 generated from previously decompressed water in order to remove the volatiles prior the 562 experiment, and the salt added to the lower layer produced an initially density-stratified system. 563 As the system decompresses and the lower layer becomes less dense, the layers overturned. In a 564 further, unpublished experiment, an enclosed two layer system was connected to an upper tank 565 through two conduits providing a pathway for each of the layers to vent from the chamber, one 566 from the lower and one from the upper layer of system. The whole system was then enclosed in 567 sealed tank connected to the vacuum pump, Initially, as the system reached the pressure at which 568 some volatiles were exsolved from the lower layer, this layer expanded and an eruption began, 569 with the dense volatile-rich lower layer erupting through the lower conduit (right hand conduit, 570 figure 7) and the less dense volatile-poor solution erupting from the upper conduit (left hand 571 conduit, figure 7). However, as the experiment persisted and more volatiles were produced in the 572 lower layer, the density of the lower layer fell below that of the upper layer, and there was a 573 short-lived overturn event in the experimental tank. At this stage, the solution erupting from the 574 two conduits switched, as shown in the last panel in figure 8. The withdrawal of a lower viscosity 575 lower magma through an upper more viscous layer during eruption was also considered by 576 (Blake and Ivey, 1986).

\subsection{Vesiculation of underplating magmas and formation of mafic enclaves}

579 In the above discussion we have assumed that there is no separation of the bubbles from the melt580 crystal-bubble mixture, and that the melt-crystal mixture behaves as if it is a single fluid phase. 581 This leads to the idealised bulk flow behaviour described above. Although this is a powerful end582 member picture of the possible controls on overturn and eruption, the possible separation of the 583 volatile phase from the melt may influence such mixing processes and also the evolution of an 584 eruption and the eruption products and we now explore such effects, considering the impact of 585 bubble separation from a crystal-poor melt (Bottinga and Javoy, 1991; Jaupart and Vergniolle, 586 1989; Menand and Phillips, 2007; Woods and Cardoso, 1997).

588 In a low crystallinity melt, gas bubbles may rise. There are two modes of separation. First, the 589 bubbles can rise individually, following Stokes law, or a modified Stokes law including effects of 


$$
V_{b} / V_{B}=b^{2} / B^{2} \Delta c
$$

603 where the Stokes speed is given by $V_{b}=2 \Delta \rho g b^{2} / 9 \mu$. Since the bubbles have typical sizes of order $b=0.1-1.0 \mathrm{~mm}$ in the chamber, the bubble rise speed is quite small, of order $10^{-10}-10^{-6}$ $\mathrm{m} / \mathrm{s}$ in magma with viscosity of order $10^{2}-10^{4} \mathrm{~Pa} \mathrm{~s}$, and so if there are small fluctuations in the concentration of bubbles through the melt layer, for example of magnitude $\Delta c=0.0001-0.01$, the convective rise speed of parcels of bubble-rich melt will exceed the individual bubble rise speed provided the length scale of the parcel, $B$ is greater than $(10-100) b \sim 0.1-10 \mathrm{~cm}$. If there are concentration fluctuations over greater length scales, as is very likely in a magma reservoir of scale 0.1 to $1.0 \mathrm{~km}$, then convective mixing may dominate the individual rise of bubbles through the melt. Although convective mixing will tend to stir the bubbles throughout the melt, leading to layer (Cardoso and Woods, 1999; Thomas et al., 1993; Woods and Cardoso, 1997). As a result, in 616 either the case of individual bubble ascent or convective separation, the bubble-melt separation occurs over times which scale as $H / V_{b}$. With bubbles of size $0.1-1.0 \mathrm{~mm}$ in a magma of viscosity $10^{2}-10^{4}$ Pas, the time to separate from a $100 \mathrm{~m}$ thick layer of melt is therefore in the range $10^{8}-$ $10^{12} \mathrm{~s}$. We infer that, with small bubbles in the more viscous melt, the time for separation may be 
621 melt. In this case, cooling and crystallization will lead to further exsolution of volatiles and a 622 build up of the chamber pressure which will tend to trigger an eruption of the bubble-laden melt. 623 In addition, the accumulation of bubbles in the lower layer of melt will lower the density of this 624 layer and tend to promote mixing or overturn of the magmas.

626 In contrast, for larger bubbles or a less viscous melt, bubble separation may occur within years, 627 and so may be a dominant process inhibiting the tendency for large-scale overturn of the magma reservoir. Indeed with more primitive magmas, which have a low viscosity, bubble-melt separation can lead to bubble accumulation at the top of the magma body and the formation of a foam or bubble-rich layer. This is a mechanism proposed to be important for volatile exsolution 631 in basaltic sills in the upper crust (Menand and Phillips, 2007), and in shallow reservoirs e.g., at 632 Kilauea Volcano (Edmonds and Gerlach, 2007). If the system is closed, then the pressure will 633 increase by a similar amount to that shown in the calculation above (section 3.2), in which the 634 volatiles in the reservoir are assumed to remain well-mixed. However, in a reservoir of significant vertical extent there may be a significant additional pressurisation associated with the migration of the bubbles to the top of the chamber and the associated decrease in magmastatic pressure experienced by the bubbles. For example, in a chamber of order $1 \mathrm{~km}$ in vertical extent, 638 bubble separation may lead to an additional overpressure of up to 1-10 MPa, but the effect is 639 smaller in chambers of smaller vertical extent (Woods and Cardoso, 1997). If the magma has 0.5$6401.0 \mathrm{wt} \% \mathrm{CO}_{2}$ and $<0.5 \mathrm{wt} \% \mathrm{H}_{2} \mathrm{O}$, and the reservoir is deeper than $2 \mathrm{~km}$, the exsolved volatile 641 phase will be enriched in $\mathrm{CO}_{2}$ relative to $\mathrm{H}_{2} \mathrm{O}$. Leakage of this exsolved volatile phase from the roof zone of the magma reservoir may cause broad regions of diffuse $\mathrm{CO}_{2}$ degassing inside calderas, as is observed at Kîlauea Volcano, Hawai'i (Gerlach et al., 2002) and at many other active volcanoes exhibiting diffuse degassing between and during eruptive episodes (Salazar et 645 al., 2001; Viveiros et al., 2010).

647 In some cases, the separation of the volatiles from the melt may then lead to a more continuous 648 'open' style of degassing of the volcanic system, either through Strombolian-style gas bursts. 649 This can serve to regulate the pressure in the chamber and may tend to suppress larger, explosive 650 eruptions. It has been proposed that if a foam layer develops at the top of a chamber or layer of 651 basaltic melt, liquid drainage through the foam can lead to merger of the bubbles in the foam, and 652 formation of larger gas slugs which may be responsible for larger Strombolian gas burst type 653 eruptions (Houghton and Gonnermann, 2008; Houghton et al., 2016; Jaupart and Vergniolle, 654 1988; Vergniolle and Jaupart, 1986). 
In section 4.1 we discussed the possibility of a large scale overturn of the system if bubbles are exsolved in the lower layer of melt and this layer of melt is sufficiently viscous to retain the majority of the bubbles until its density falls below that of the upper layer. However, in some systems, there will be partial separation of the gas phase from the lower layer of melt, as described above, and this can lead to accumulation of a foam at the interface between the two layers of melt, especially if the upper layer is more viscous. If a sufficient fraction of the bubbles separate from the lower layer of melt, it may remain denser than the upper layer, suppressing any large scale overturn, while the foam forming at the interface between the layers will typically be less dense than the overlying layer of melt, leading to convective instability and ascent of parcels of foam into the overlying layer of melt. The percolation of a hot exsolved volatile phase from a mafic underplating layer upward into cooler, crystal-rich magma body has been proposed as a mechanism by which cool near-solidus magmas may 'defrost', triggering eruption (Bachmann and Bergantz, 2006; Huber et al., 2011; Huber et al., 2010). The exsolved volatile phase may also carry some of the mafic melt into the upper layer, leading to the formation of mafic inclusions in the upper layer (Andrews and Manga, 2014; Bacon, 1986; Eichelberger, 1980; Plail et al., 2014). These may eventually erupt if the overall pressure of the system becomes sufficient to trigger eruption of the upper layer (Phillips and Woods, 2002; Thomas et al., 1993). Good evidence for the accumulation of a foam layer at the interface between underplating basalts and overlying crystal-rich andesite comes from the observation, from enclaves erupted in Soufrière Hills Volcano andesite, that the enclaves are enriched in magnetite, interpreted to be due to the nucleation of aqueous fluid bubbles onto magnetite, which then "floated" up to the interface (Edmonds et al., 2014a).

Recently, it has been found that some mafic (basalt to basaltic andesite) inclusions (hosted in crystal-rich andesites at Soufrière Hills Volcano, Montserrat) are themselves composed of a mixture of the upper and lower melt (Plail et al., 2018), and this suggests that there is some mixing or intermingling of the magmas in either the foam layer or the lower layer prior to the formation of the mafic inclusions in the upper layer. This observation is common to many andesites containing mafic inclusions, such as the erupted products of Quizapu (Ruprecht et al., 2012) and Unzen, Japan (Browne et al., 2005). This intermingling of the magmas prior to formation of a mafic inclusion may arise if crystals in the upper layer become stirred into the lower layer. These are observed in the enclaves as plagioclase crystals with sieve textures and resorbed rims that have undergone heating after being mixed into more mafic melt (Humphreys 
et al., 2009), which is a common feature of many mafic inclusions hosted by andesites and 690 dacites (Leonard et al., 2002; Tepley et al., 1999). As the lower layer becomes progressively 691 more crystalline and volatile-rich, a foamy layer may develop at the interface, carrying some of 692 the hybrid interface magma up with the bubbles into the upper layer. Alternatively, when the 693 mafic magma ponds below the existing layer of cooler and less dense melt, the heat transfer 694 across the interface may lead to formation of a thin layer of relatively hot and mobile original 695 magma and a corresponding thin layer of cooled, more crystalline and volatile-rich new magma 696 which supplies the heat to the upper thin layer. Eventually, the lower cooled layer exsolves some 697 volatiles, becomes less dense and intermingles with the heated boundary layer of original magma. 698 This local overturn can produce intermingling and a hybrid layer of melt. As the heat transfer 699 continues, the boundary layer becomes progressively deeper, enabling buoyant plumes from the 700 intermingled boundary layer to rise into the upper, cooler layer of more viscous melt. As the 701 boundary layer becomes deeper, mafic enclaves may become larger. In this multistage fashion, 702 we can envisage that mafic inclusions of intermediate composition may be generated in the upper 703 layer (Plail et al., 2018).

Whether wholescale overturn of magmas occurs, or whether gas-rich buoyant plumes (or even 706 fractures, see next section) are generated from the interface between magmas, it seems clear that 707 underplating basaltic magmas may supply significant quantities of exsolved volatiles to overlying magma reservoirs. Owing to the high sulfur content at sulfide saturation of basaltic melts (Jugo, 2009; Ripley and Li, 2013) it has been suggested that mafic underplating magmas may be an

711 sulfur-rich magmatic exsolved volatile phase to the overlying more evolved magma (Edmonds et 712 al., 2010; Pallister et al., 1992; Roberge et al., 2009). Underplating mafic magmas, under some 713 circumstances, may also play a role in generating more $\mathrm{CO}_{2}$-rich magmatic vapor which may flux 714 through shallower crystal-rich magmas (Blundy et al., 2010). The supply of volatiles from 715 underplating mafic magmas has also been linked to the formation of copper porphyries. While 716 crystal-rich, evolved magmas have capacity for producing the mass of copper required for a 717 viable economic deposit, it has been suggested that additional sources of sulfur may be necessary, 718 which may be supplied by mafic magmas intruding the evolved magma reservoir (Blundy et al., 719 2015; Hattori and Keith, 2001).

\section{5. Exsolved volatile phase generation and transport through crystal-rich magma bodies}


Magma bodies may spend much of their time in the crust near their solidus temperature, in a 723 partially or entirely crystalline state (Cashman et al., 2017; Cooper and Kent, 2014; Huber et al., 724 2011; Huber et al., 2009; Huber et al., 2010; Koyaguchi and Kaneko, 1999; Marsh, 1981).

725 Volatile-rich basalts rising up into the crust will tend to underplate and interact with such 726 crystalline magma bodies (Bachmann and Bergantz, 2006; Edmonds et al., 2014b; Huber et al., 727 2011), as discussed above. In this section we review and explore the range of behaviours possible 728 for storage and transport of the exsolved volatile phase in a crystal-rich mush and discuss the 729 implications for gas storage in and/or segregation from a mush, large syn-eruptive sulfur 730 emissions, ore deposits and the role of basaltic underplating in supplying volatiles to large, long731 lived crystalline magma bodies.

\subsection{Transport of an exsolved volatile phase in crystal-rich magma}

734 An underplating basalt will tend to pond and spread out beneath a cooler, less dense, more 735 evolved magma. The basalt will cool and crystallise against the cooler magma, generating a buoyant volatile phase that may accumulate at the interface or rise upward, as described in section 4. The rate of volatile injection into the overlying crystal-rich magma depends on the volatile content of the melt, the cooling rate and the convective motion of the underplating magma (Cardoso and Woods, 1999; Huppert et al., 1982). The accumulation of an exsolved volatile phase at the interface may cause a rheological instability, eventually leading to the foam layer becoming buoyant and rising upward into the crystal-rich magma. It has been proposed that the migration of this exsolved volatile phase into the overlying magma may remobilise the crystal-rich magma due to the transfer of heat and partial melting (Bachmann and Bergantz, 2006; Huber et al., 2011; Huber et al., 2010). Reactivation and eruption of crystal-rich magmas may be triggered in this way (Couch et al., 2001; Murphy et al., 2000; Pallister et al., 1992), with

746 the underplating basalt supplying volatiles which may be outgassed during the eruption 747 (Christopher et al., 2010; Edmonds et al., 2010).

As magma evolves and becomes progressively more crystalline, it is able to support a yield stress and form a crystal framework (Caricchi et al., 2007; Lejeune and Richet, 1995; Pistone et al., 2012) which tends to suppress the convective mixing or the ascent of bubbles. Such effects may begin with crystal volume fractions of $0.2-0.3$, depending on the shape and morphology of the crystals, and as the crystal content increases, the yield stress increases (Pistone et al., 2012). In addition, the viscosity of the crystalline mixture tends to be very much larger than the pure melt, suppressing shear motions in the suspension. Recent experimental work has shown, however, that 
the presence of hydrous fluid bubbles in a mush may have significant effects on its rheology. For mushes with crystal fractions of 0.55 to 0.7 , for example, addition of volatiles such that bubble volume fractions of up to 0.1 are generated, leads to a dramatic reduction in viscosity by 3-4 orders of magnitude (Pistone et al., 2013). Furthermore, the viscosity of such three phase systems may be strain rate-dependent, with both shear thinning and shear thickening behaviour observed under different strain rates and crystal contents (Pistone et al., 2013).

As a result of this complex rheology, the process of gas separation from the crystal-rich magma takes on a range of forms. In a crystalline matrix, the migration process may be associated with either (a) gas flow through the porous matrix, which is likely to be a relatively slow process, owing to the low permeability of the formation (Parmigiani et al., 2016; Parmigiani et al., 2014) or (b) the generation of small effective fractures or cracks in the crystal-framework as the pressure exceeds the yield stress or effective fracture stress (Barth et al., in review; Huber et al., 2011). Such cracks then provide much higher permeability pathways through which an exsolved volatile phase may flow (Oppenheimer et al., 2015).

In more crystalline melts, these transport processes, which may be relatively rapid, may be responsible for the separation of the exsolved volatile phase from the melt and its accumulation at the roof zone, or in liquid-rich lenses in the magma reservoir system, where they may be held up (Parmigiani et al., 2016). These accumulations of exsolved volatiles may lead to large emissions of volcanic gases during eruptions. If the exsolved volatile phase at this pressure has a significant concentration of sulfur (Oppenheimer et al., 2011; Scaillet and Pichavant, 2003) then this mechanism of gas extraction may rationalise the high sulphur dioxide emissions from, for example, large explosive eruptions such as El Chichon (Mexico, 1982) (Bluth et al., 1997) and Pinatubo (Philippines, 1991) (Wallace and Gerlach, 1994). It is also likely that volcanoes which exhibit long-lived and persistent degassing, both during and between eruptions, may be tapping regions of crystal-rich magma reservoirs that have accumulated exsolved volatiles (Christopher et al., 2015; Edmonds et al., 2003).

In a series of experiments to model the in situ production of an exsolved volatile phase in a cooling and crystallising melt, a series of glass balls were placed in a tank filled with polymerrich liquid and the mixture was gradually decompressed (Ptacek et al., 2018, sub judice). As the mixture reached the vapour-saturation pressure, volatiles gradually came out of solution and as the pressure was slowly decreased, the pack of beads gradually inflated. As this dilation occurred, 
790 the effective permeability of the particle pack increased substantially and the gas was able to 791 migrate through the interstices between the glass beads, forming small gas channels in the matrix.

792 Once the gas escape rate exceeded the bubble generation rate, the expansion of the system was 793 arrested and indeed the gas-derived dilation reduced (panel 3, figure 9). In this way the gas was 794 able to separate from the melt-crystal mixture, and the pack relaxed back to a depth at which the 795 remaining gas phase was trapped as individual bubbles in the interstices between crystals, as may 796 be seen in panel 4 of figure 9 (Ptacek et al., 2018, sub judice).

798 The processes controlling the rate of migration of gas through such a deformable permeable 799 matrix may involve both a regime of slow capillary gas flow through the permeable matrix 800 (Parmigiani et al., 2016) and a regime of more rapid gas flow following deformation of the pack 801 in which high permeability channels are created (Oppenheimer et al 2016). In the analogue 802 system of a clay-water mixture, the continued supply of gas to a clay-filled elastic reservoir may 803 lead to episodic pressurisation of the reservoir, followed by fracture of the clay seal, gas release 804 and build up of a further pressurisation cycle (Rocco et al., 2017). This process may be 805 analoguous to the intermittent gas-escape cycles which develop in a magmatic system as gas 806 pressure builds up and eventually exceeds the yield strength of the viscous-crystalline melt, 807 driving a pure gas channel through the particle-pack and allowing the system to decompress. A 808 similar phenomenon arises when gas is supplied from below to a close-packed mixture of 809 particles suspended in a high-viscosity liquid (Barth et al., in review). The gas tends to 810 accumulate in localised pockets within the deformable liquid-crystal pack. As the pressure builds 811 up, it is eventually able to generate a small fracture which provides a pathway through the 812 system, allowing the gas to continue rising through the formation, until the overpressure is 813 dissipated and the gas builds up a new pocket higher in the system.

815 These experiments of the migration of gas through a highly crystalline permeable matrix, 816 partially filled with melt, leads to a different mechanism of gas separation from underplating 817 basalts as the melt cools and crystallises. For a typical crystalline matrix, which is poorly 818 consolidated, the fracture strength or yielding strength may be of order $10^{5}-10^{6} \mathrm{~Pa}$ (Saar et al., 819 2001), which is smaller than the strength of a solid rock. As exsolved gases form and pressurize 820 the system they will therefore be able to open up fractures within the basalt along which they may 821 escape. We deduce that if a new intrusion of basalt cools and crystallises to the extent that it 822 becomes immobile or develops a yield stress while remaining denser than the overlying layer of 
melt, then as volatiles are exsolved from this layer of melt, these volatiles can be transported via fractures into the overlying original magma, as discussed by Huber et al., (2012).

A further phenomenon associated with gas migration through crystalline magmas is that, once the main pulse of gas has passed through the magma, there will be a small fraction which is retained in the pore spaces by capillary effects, and this will lead to the magma remaining in a more compressible state than the pure volatile-free melt phase. Typically the residual saturation of gas in a porous layer depends on the grain size and the interfacial tension between the solid minerals and the melt phase. More experimental data is required to constrain these gas fractions, which depend on the wetting angle of the gas and crystals relative to that of the melt and crystals.

The exsolved volatile phase may also play a role in magma differentiation and crystal-liquid segregation in undercooled magmatic intrusions and in thin sheets of primitive magma underplating cooler magma reservoirs: as the magma cools and crystallises, the buildup of gas pressure due to second boiling may be relieved by expulsion of melt out of the region of crystallization (Anderson Jr et al., 1984; Sisson and Bacon, 1999).

\subsection{Implications of our new understanding of the transport of the exsolved volatile phase} through crystalline magmas for ore deposits

The exsolved magmatic volatile phase is understood to play a critical role in the formation of porphyries which contain economic grades of metal deposits (Hedenquist and Lowenstern, 1994; Lowenstern et al., 1991; Williams-Jones and Heinrich, 2005). Recent advances, discussed above, in understanding how the exsolved volatile phase may be retained, and/or transported through crystal-rich magma bodies have important implications for models of ore deposit formation and for understanding why some magma reservoirs yield metal accumulations of economic importance and others do not. As discussed in section 2, magma may saturate in an exsolved volatile phase during decompression, or during cooling and crystallization. Depending on the initial $\mathrm{H}_{2} \mathrm{O}$ and chlorine contents of the melt, and the pressure and temperature, a brine phase may also form (Webster, 1997, Metrich and Rutherford, 1992, Webster, 1992, Shinohara, 1994). The chlorinity of the exsolved volatile phase is critical for its metal-carrying capacity (Halter and Webster, 2004). The exsolved volatile phase may migrate to the upper reaches of the magma reservoir system through channelised flow through a crystal-rich magma, perhaps accumulating in pockets before rising further up through the mush, as discussed in section 5. Over time, the lower density exsolved volatile phase will accumulate in the upper zones of the reservoir, or in 
liquid lenses, where fracturing cannot occur (Parmigiani et al., 2016). This process of fluid migration through quasi-brittle fractures may be much faster than by bubble rise through permeable flow or through magma convection (Lowenstern, 1994; Shinohara et al., 1995). This therefore provides an efficient mechanism for segregation and accumulation of metals carried by saline, low density, exsolved fluids at the roof zones of mushy magma reservoirs (figure 10).

The "tonnage" of metals that may be accumulated in this way might then be expected to be proportional to the water content of the magma, which will determine the mass fraction of exsolved volatile phase, its chlorinity, which will depend on the chlorine content of the melt, temperature and pressure, the overall size of the magma reservoir and perhaps just as importantly, the crystallinity and structure of the reservoir. Extensive mush zones will allow rapid and efficient transport of metal-rich magmatic vapor to the roof zones of magma reservoirs, where excess pressure there will promote the intrusion of stocks and/or the triggering of volcanic eruptions.

872 For example, porphyries hosting molybdenum (Mo) deposits are formed from highly evolved, 873 crystal-rich magmas, whereby Mo partitions from the silicate melt into a co-existing single fluid, 874 at pressures above the critical point, with a fluid-melt partition coefficient of 5-20 (Audetat and Li, 2017; Zajacz et al., 2008). At lower pressures or temperatures, as the solidus is approached, this fluid may condense a brine phase. There is abundant evidence for extensive fluid transport at magmatic conditions: Mo mineralization commonly occurs only in the uppermost parts of vertically elongate magma bodies. The available data from a recent review of a number of Mo porphyries suggest that the parent magmas of such bodies were not particularly Mo-rich and the

880 fluids from both mineralising and barren magma bodies are similar in terms of their geochemistry 881 (Audétat and Li, 2017; Lowenstern, 1994), suggesting that instead, magma volume and depth, as well as the mechanism of volatile extraction from the mush, may be the most important factor.

883 Previous workers have suggested magma convection and open system degassing as a mechanism 884 for extracting the fluid phase from a large body of magma (Lowenstern, 1994; Shinohara et al., 885 1995). However, following recent work, as discussed above, on the mechanisms of porous flow 886 and fracturing of crystal-rich magma, we now understand that fluid extraction from large-scale 887 mush systems may take place efficiently on rapid timescales, thereby building accumulations of metals at the roof zones of large crystal-rich magma bodies (Huber et al., 2012).

\section{Summary and problems for the future}


891 In this review we have described some of the complex processes associated with the dynamical interactions of melt, crystals and volatiles. We show that most magmas, particularly those in

893 subduction zone settings, are in equilibrium with an exsolved vapor phase through much of the 894 evolution from the mid-crust to the surface and this exsolved volatile phase plays a fundamental 895 role in magma differentiation, eruption triggering and the formation of hydrothermal ore deposits.

896 We have distinguished between low crystal content, fluid-like systems in which the gas may 897 drive convection in the melt, and higher crystal content, mushy systems, in which the gas may 898 migrate by permeable flow or along fractures through the mush. We have also emphasized the 899 role of exsolved volatiles in regulating the density and pressure of the magma and the chamber, 900 with the exsolved volatile phase constraining the compressibility of the magma reservoir and the 901 volume of melt erupted, given the change in volume of the magma chamber. Density changes in a 902 stratified magma reservoir can lead to overturn or mixing and the formation of mafic inclusions 903 especially in the case of fluid-like melt; whereas with a more crystalline system, density reversals 904 may be less effective in that the convective overturn requires a buoyancy-derived stress to exceed 905 the yield stress of the crystal-pack. However, if a series of fractures or channels open up to allow 906 the exsolved volatiles to leak from the melt-crystal mixture, this can stabilise the vertical density 907 profile of the magma reservoir over time. This mechanism of exsolved volatile phase migration 908 to the apical zones of a magma reservoir over time can reconcile observations of large and/or 909 persistent sulfur dioxide fluxes from volcanoes, as well as rapid timescales for the formation of 910 hydrothermal ore deposits (e..g $\mathrm{Cu}$ porphyry-type deposits). Future work in this area might 911 involve the use of volatile radionuclides at actively degassing volcanoes to establish the likely 912 timescales of exsolved volatile accumulation in magma reservoirs.

914 There have been a series of key experiments measuring the shear stress in crystalline and crystal915 bubble mixtures subjected to shear (Pistone et al., 2013), and some more recent experiments 916 exploring the migration of gas through crystal-melt suspensions (Barth et al., in review; 917 Oppenheimer et al., 2015; Ptacek et al., 2018, sub judice), but there is much more to learn about 918 the macro-scale dynamics of the bulk fluid and how this interacts with the local dynamics of gas919 melt separation, which can be facilitated through local deformation and fracture formation. Field 920 observations of deformed bubbles and apparent shear bands in which melt is localized provide 921 critical clues about the local processes of deformation and their relation to the large scale flow. 922 Such observations suggest that there may also be critical effects associated with the varying 923 compressibility of the magma as it ascends through the crust, and decompresses, perhaps leading 924 to waves of volatile-rich and volatile-poor magma, connected by local shear bands or fractures. 
The physical processes controlling crystal-rich magmas offers an area ripe for novel laboratory experiments, and these, combined with new field observations and careful geochemical analysis may be key in future efforts to unravel the history of co-erupted gas, melt and crystals.

\section{Acknowledgements}

930 We are grateful for support from the BP Institute, University of Cambridge.

\section{References}

Anderson, A.T., 1995. $\mathrm{CO}_{2}$ and the eruptibility of picrite and komatiite. Lithos, 34(1-3): 19-25.

Anderson Jr, A.T., Swihart, G.H., Artioli, G. and Geiger, C.A., 1984. Segregation vesicles, gas filter-pressing, and igneous differentiation. The Journal of Geology, 92(1): 55-72.

Anderson, K. and Segall, P., 2011. Physics-based models of ground deformation and extrusion rate at effusively erupting volcanoes. Journal of Geophysical Research: Solid Earth, 116(B7).

Andrews, B.J. and Manga, M., 2014. Thermal and rheological controls on the formation of mafic enclaves or banded pumice. Contr. Mineral. and Petrol., 167(1): 961.

Atlas, Z.D., Dixon, J.E., Sen, G., Finny, M. and Martin-Del Pozzo, A.L., 2006. Melt inclusions from Volcán Popocatépetl and Volcán de Colima, Mexico: melt evolution due to vaporsaturated crystallization during ascent. Journal of Volcanology and Geothermal Research, 153(3-4): 221-240.

Audétat, A. and Li, W., 2017. The genesis of Climax-type porphyry Mo deposits: insights from fluid inclusions and melt inclusions. Ore Geology Reviews.

Bachmann, O. and Bergantz, G.W., 2006. Gas percolation in upper-crustal silicic crystal mushes as a mechanism for upward heat advection and rejuvenation of near-solidus magma bodies. Journal of Volcanology and Geothermal Research, 149(1): 85-102.

Bacon, C.R., 1986. Magmatic inclusions in silicic and intermediate volcanic rocks. Journal of Geophysical Research: Solid Earth, 91(B6): 6091-6112.

Bali, E., Hartley, M., Halldórsson, S., Gudfinnsson, G. and Jakobsson, S., 2018. Melt inclusion constraints on volatile systematics and degassing history of the 2014-2015 Holuhraun eruption, Iceland. Contr. Mineral. and Petrol., 173(2): 9.

Barclay, J., Carroll, M., Rutherford, M., Murphy, M., Devine, J., Gardner, J. and Sparks, R., 1998. Experimental phase equilibria constraints on pre-eruptive storage conditions of the Soufreiere Hills magma. Geophysical Research Letters(25): 3437-3440.

Barmin, A., Melnik, O. and Sparks, R., 2002. Periodic behavior in lava dome eruptions. Earth and Planetary Science Letters, 199(1-2): 173-184.

Barth, A., Edmonds, M. and Woods, A.W., in review. Valve-like dynamics of gas flow through a packed crystal mush and cyclic Strombolian explosions. Nature Communications.

Berkowitz and Woods, A., 2018 under review.

Berlo, K., Stix, J., Roggensack, K. and Ghaleb, B., 2012. A tale of two magmas, Fuego, Guatemala. Bull Volcanol, 74(2): 377-390.

Biggs, J. and Pritchard, M.E., 2017. Global volcano monitoring: what does it mean when volcanoes deform? Elements, 13(1): 17-22.

Blake, S., 1984. Volatile oversaturation during the evolution of silicic magma chambers as an eruption trigger. Journal of Geophysical Research: Solid Earth, 89(B10): 8237-8244. 
Blake, S. and Ivey, G.N., 1986. Magma-mixing and the dynamics of withdrawal from stratified reservoirs. Journal of Volcanology and Geothermal Research, 27(1-2): 153-178.

Blundy, J. and Cashman, K., 2005. Rapid decompression-driven crystallization recorded by melt inclusions from Mount St. Helens volcano. Geology, 33(10): 793-796.

Blundy, J., Cashman, K.V., Rust, A. and Witham, F., 2010. A case for CO 2-rich arc magmas. Earth and Planetary Science Letters, 290(3): 289-301.

Blundy, J., Mavrogenes, J., Tattitch, B., Sparks, S. and Gilmer, A., 2015. Generation of porphyry copper deposits by gas-brine reaction in volcanic arcs. Nature Geoscience, 8(3): 235-240.

Bluth, G.J., Rose, W.I., Sprod, I.E. and Krueger, A.J., 1997. Stratospheric loading of sulfur from explosive volcanic eruptions. The Journal of Geology, 105(6): 671-684.

Botcharnikov, R., Linnen, R. and Holtz, F., 2010. Solubility of Au in Cl-and S-bearing hydrous silicate melts. Geochimica et Cosmochimica Acta, 74(8): 2396-2411.

Bottinga, Y. and Javoy, M., 1991. The degassing of Hawaiian tholeiite. Bull Volcanol, 53(2): 7385.

Bower, S.M. and Woods, A.W., 1998. On the influence of magma chambers in controlling the evolution of explosive volcanic eruptions. Journal of Volcanology and Geothermal Research, 86(1): 67-78.

Brantley, S. and Myers, B., 2000. Mount St. Helens-from the 1980 eruption to 2000. 2327-6932, US Geological Survey.

Browne, B.L., Eichelberger, J.C., Patino, L.C., Vogel, T.A., Dehn, J., Uto, K. and Hoshizumi, H., 2005. Generation of porphyritic and equigranular mafic enclaves during magma recharge events at Unzen Volcano, Japan. Journal of Petrology, 47(2): 301-328.

Bucholz, C.E., Gaetani, G.A., Behn, M.D. and Shimizu, N., 2013. Post-entrapment modification of volatiles and oxygen fugacity in olivine-hosted melt inclusions. Earth and Planetary Science Letters.

Burgisser, A., Alletti, M. and Scaillet, B., 2015. Simulating the behavior of volatiles belonging to the $\mathrm{C}-\mathrm{O}-\mathrm{H}-\mathrm{S}$ system in silicate melts under magmatic conditions with the software DCompress. Computers \& Geosciences, 79: 1-14.

Burgisser, A. and Bergantz, G.W., 2011. A rapid mechanism to remobilize and homogenize highly crystalline magma bodies. Nature, 471(7337): 212-215.

Candela, P.A., 1997. A review of shallow, ore-related granites: textures, volatiles, and ore metals. Journal of petrology, 38(12): 1619-1633.

Cardoso, S.S.S. and Woods, A.W., 1999. On convection in a volatile-saturated magma. Earth and Planetary Science Letters, 168(3-4): 301-310.

Caricchi, L., Burlini, L., Ulmer, P., Gerya, T., Vassalli, M. and Papale, P., 2007. Non-Newtonian rheology of crystal-bearing magmas and implications for magma ascent dynamics. Earth and Planetary Science Letters, 264(3): 402-419.

Caricchi, L., Sheldrake, T.E. and Blundy, J., 2018. Modulation of magmatic processes by CO 2 flushing. Earth and Planetary Science Letters, 491: 160-171.

Carn, S., Clarisse, L. and Prata, A., 2016. Multi-decadal satellite measurements of global volcanic degassing. Journal of Volcanology and Geothermal Research, 311: 99-134.

Carroll, M. and Rutherford, M., 1985. Sulfide and sulfate saturation in hydrous silicate melts. Journal of Geophysical Research: Solid Earth (1978-2012), 90(S02): C601-C612.

Cashman, K. and Blundy, J., 2000. Degassing and crystallization of ascending andesite and dacite. Philosophical Transactions of the Royal Society of London. Series A: Mathematical, Physical and Engineering Sciences, 358(1770): 1487-1513.

Cashman, K. and Blundy, J., 2013. Petrological cannibalism: the chemical and textural consequences of incremental magma body growth. Contr. Mineral. and Petrol., 166(3): 703-729.

Cashman, K.V., 2004. Volatile controls on magma ascent and eruption. The State of the Planet: Frontiers and Challenges in Geophysics: 109-124. 
Cashman, K.V., Sparks, R.S.J. and Blundy, J.D., 2017. Vertically extensive and unstable magmatic systems: A unified view of igneous processes. Science, 355(6331): eaag3055.

Cassidy, M., Edmonds, M., Watt, S.F., Palmer, M.R. and Gernon, T.M., 2015. Origin of Basalts by Hybridization in Andesite-dominated Arcs. Journal of Petrology: egv002.

Chiaradia, M., Ulianov, A., Kouzmanov, K. and Beate, B., 2012. Why large porphyry Cu deposits like high $\mathrm{Sr} / \mathrm{Y}$ magmas? Scientific reports, 2: 685.

Chiodini, G., Caliro, S., De Martino, P., Avino, R. and Gherardi, F., 2012. Early signals of new volcanic unrest at Campi Flegrei caldera? Insights from geochemical data and physical simulations. Geology, 40(10): 943-946.

Christopher, T., Blundy, J., Cashman, K., Cole, P., Edmonds, M., Smith, P., Sparks, R. and Stinton, A., 2015. Crustal-scale degassing due to magma system destabilization and magma-gas decoupling at Soufrière Hills Volcano, Montserrat. Geochemistry, Geophysics, Geosystems.

Christopher, T., Edmonds, M., Humphreys, M. and Herd, R.A., 2010. Volcanic gas emissions from Soufrière Hills Volcano, Montserrat 1995-2009, with implications for mafic magma supply and degassing. Geophysical Research Letters, 37(19).

Clémente, B., Scaillet, B. and Pichavant, M., 2004. The solubility of sulphur in hydrous rhyolitic melts. Journal of Petrology, 45(11): 2171-2196.

Coombs, M.L., Eichelberger, J.C. and Rutherford, M.J., 2000. Magma storage and mixing conditions for the 1953-1974 eruptions of Southwest Trident volcano, Katmai National Park, Alaska. Contr. Mineral. and Petrol., 140(1): 99-118.

Cooper, K.M. and Kent, A.J., 2014. Rapid remobilization of magmatic crystals kept in cold storage. Nature.

Cordell, D., Unsworth, M.J. and Díaz, D., 2018. Imaging the Laguna del Maule Volcanic Field, central Chile using magnetotellurics: Evidence for crustal melt regions laterally-offset from surface vents and lava flows. Earth and Planetary Science Letters, 488: 168-180.

Costa, F., Andreastuti, S., de Maisonneuve, C.B. and Pallister, J.S., 2013. Petrological insights into the storage conditions, and magmatic processes that yielded the centennial 2010 Merapi explosive eruption. Journal of Volcanology and Geothermal Research, 261: 209235.

Couch, S., Sparks, R. and Carroll, M., 2001. Mineral disequilibrium in lavas explained by convective self-mixing in open magma chambers. Nature, 411(6841): 1037-1039.

Davidson, J.P. and Tepley, F.J., 1997. Recharge in volcanic systems: evidence from isotope profiles of phenocrysts. Science, 275(5301): 826-829.

De Maisonneuve, C.B., Dungan, M., Bachmann, O. and Burgisser, A., 2012. Insights into shallow magma storage and crystallization at Volcán Llaima (Andean Southern Volcanic Zone, Chile). Journal of Volcanology and Geothermal Research, 211: 76-91.

Degruyter, W. and Huber, C., 2014. A model for eruption frequency of upper crustal silicic magma chambers. Earth and Planetary Science Letters, 403: 117-130.

Dingwell, D., Romano, C. and Hess, K.-U., 1996. The effect of water on the viscosity of a haplogranitic melt under PTX conditions relevant to silicic volcanism. Contr. Mineral. and Petrol., 124(1): 19-28.

Dingwell, D.B., 1996. Volcanic dilemma: flow or blow? Science, 273(5278): 1054.

Dixon, J.E., Clague, D.A. and Stolper, E.M., 1991. Degassing history of water, sulfur, and carbon in submarine lavas from Kīlauea Volcano, Hawaii. The Journal of Geology: 371-394.

Dixon, J.E. and Stolper, E.M., 1995. An experimental study of water and carbon dioxide solubilities in mid-ocean ridge basaltic liquids. Part II: applications to degassing. Journal of Petrology, 36(6): 1633-1646.

Dixon, J.E., Stolper, E.M. and Holloway, J.R., 1995. An experimental study of water and carbon dioxide solubilities in mid-ocean ridge basaltic liquids. Part I: calibration and solubility models. Journal of Petrology, 36(6): 1607-1631. 
Edmonds, M., Aiuppa, A., Humphreys, M., Moretti, R., Giudice, G., Martin, R., Herd, R. and Christopher, T., 2010. Excess volatiles supplied by mingling of mafic magma at an andesite arc volcano. Geochemistry, Geophysics, Geosystems, 11(4).

Edmonds, M., Brett, A., Herd, R., Humphreys, M. and Woods, A., 2014a. Magnetite-bubble aggregates at mixing interfaces in andesite magma bodies. Geological Society, London, Special Publications, 410: SP410. 417.

Edmonds, M. and Gerlach, T.M., 2007. Vapor segregation and loss in basaltic melts. Geology, 35(8): 751-754.

Edmonds, M., Humphreys, M.C., Hauri, E.H., Herd, R.A., Wadge, G., Rawson, H., Ledden, R., Plail, M., Barclay, J. and Aiuppa, A., 2014b. Pre-eruptive vapour and its role in controlling eruption style and longevity at Soufrière Hills Volcano. Geological Society, London, Memoirs, 39(1): 291-315.

Edmonds, M., Kohn, S., Hauri, E., Humphreys, M. and Cassidy, M., 2016. Extensive, water-rich magma reservoir beneath southern Montserrat. Lithos, 252: 216-233.

Edmonds, M., Oppenheimer, C., Pyle, D., Herd, R. and Thompson, G., 2003. SO 2 emissions from Soufrière Hills Volcano and their relationship to conduit permeability, hydrothermal interaction and degassing regime. Journal of Volcanology and Geothermal Research, 124(1): 23-43.

Edmonds, M., Pyle, D. and Oppenheimer, C., 2001. A model for degassing at the Soufrière Hills Volcano, Montserrat, West Indies, based on geochemical data. Earth and Planetary Science Letters, 186(2): 159-173.

Eichelberger, J., 1980. Vesiculation of mafic magma during replenishment of silicic magma reservoirs. Nature, 288(5790): 446-450.

Esposito, R., Hunter, J., Schiffbauer, J.D. and Bodnar, R.J., 2014. An assessment of the reliability of melt inclusions as recorders of the pre-eruptive volatile content of magmas. American Mineralogist, 99(5-6): 976-998.

Fries Jr, C., 1953. Volumes and weights of pyroclastic material, lava, and water erupted by Paricutin volcano, Michoacan, Mexico. Eos, Transactions American Geophysical Union, 34(4): 603-616.

Gaetani, G.A., O’Leary, J.A., Shimizu, N., Bucholz, C.E. and Newville, M., 2012. Rapid reequilibration of $\mathrm{H} 2 \mathrm{O}$ and oxygen fugacity in olivine-hosted melt inclusions. Geology, 40(10): 915-918.

Gerlach, T.M., 1980. Evaluation of volcanic gas analyses from Kīlauea volcano. Journal of Volcanology and Geothermal Research, 7(3-4): 295-317.

Gerlach, T.M., McGee, K.A., Elias, T., Sutton, A.J. and Doukas, M.P., 2002. Carbon dioxide emission rate of Kîlauea Volcano: Implications for primary magma and the summit reservoir. Journal of Geophysical Research: Solid Earth, 107(B9): 2189.

Ghiorso, M.S. and Gualda, G.A., 2015. An H2O-CO2 mixed fluid saturation model compatible with rhyolite-MELTS. Contr. Mineral. and Petrol., 169(6): 1-30.

Grove, T., Parman, S., Bowring, S., Price, R. and Baker, M., 2002. The role of an H 2 O-rich fluid component in the generation of primitive basaltic andesites and andesites from the Mt. Shasta region, N California. Contr. Mineral. and Petrol., 142(4): 375-396.

Guo, H. and Audétat, A., 2017. Transfer of volatiles and metals from mafic to felsic magmas in composite magma chambers: An experimental study. Geochimica et Cosmochimica Acta, 198: 360-378.

Halter, W.E. and Webster, J.D., 2004. The magmatic to hydrothermal transition and its bearing on ore-forming systems. Elsevier.

Hartley, M.E., Maclennan, J., Edmonds, M. and Thordarson, T., 2014. Reconstructing the deep $\mathrm{CO}<\mathrm{sub}>2</$ sub $>$ degassing behaviour of large basaltic fissure eruptions. Earth and Planetary Science Letters, 393: 120-131. 
Hartley, M.E., Neave, D.A., Maclennan, J., Edmonds, M. and Thordarson, T., 2015. Diffusive hydration of olivine-hosted melt inclusions. Earth and Planetary Science Letters, 425: $168-178$.

Hattori, K.H. and Keith, J.D., 2001. Contribution of mafic melt to porphyry copper mineralization: evidence from Mount Pinatubo, Philippines, and Bingham Canyon, Utah, USA. Mineralium Deposita, 36(8): 799-806.

Hautmann, S., Witham, F., Christopher, T., Cole, P., Linde, A.T., Sacks, I.S. and Sparks, R.S.J., 2014. Strain field analysis on Montserrat (WI) as tool for assessing permeable flow paths in the magmatic system of Soufrière Hills Volcano. Geochemistry, Geophysics, Geosystems, 15(3): 676-690.

Hawkesworth, C., Blake, S., Evans, P., Hughes, R., Macdonald, R., Thomas, L., Turner, S. and Zellmer, G., 2000. Time scales of crystal fractionation in magma chambers-integrating physical, isotopic and geochemical perspectives. Journal of Petrology, 41(7): 991-1006.

Hedenquist, J.W. and Lowenstern, J.B., 1994. The role of magmas in the formation of hydrothermal ore deposits. Nature, 370(6490): 519-527.

Houghton, B. and Gonnermann, H., 2008. Basaltic explosive volcanism: constraints from deposits and models. Chemie der Erde-Geochemistry, 68(2): 117-140.

Houghton, B., Taddeucci, J., Andronico, D., Gonnermann, H., Pistolesi, M., Patrick, M., Orr, T., Swanson, D., Edmonds, M. and Gaudin, D., 2016. Stronger or longer: Discriminating between Hawaiian and Strombolian eruption styles. Geology, 44(2): 163-166.

Huber, C., Bachmann, O. and Dufek, J., 2011. Thermo-mechanical reactivation of locked crystal mushes: Melting-induced internal fracturing and assimilation processes in magmas. Earth and Planetary Science Letters, 304(3): 443-454.

Huber, C., Bachmann, O. and Manga, M., 2009. Homogenization processes in silicic magma chambers by stirring and mushification (latent heat buffering). Earth and Planetary Science Letters, 283(1): 38-47.

Huber, C., Bachmann, O. and Manga, M., 2010. Two competing effects of volatiles on heat transfer in crystal-rich magmas: thermal insulation vs defrosting. Journal of Petrology, 51(4): 847-867.

Huber, C., Bachmann, O., Vigneresse, J.L., Dufek, J. and Parmigiani, A., 2012. A physical model for metal extraction and transport in shallow magmatic systems. Geochemistry, Geophysics, Geosystems, 13(8).

Humphreys, M.C., Christopher, T. and Hards, V., 2009. Microlite transfer by disaggregation of mafic inclusions following magma mixing at Soufrière Hills volcano, Montserrat. Contr. Mineral. and Petrol., 157(5): 609-624.

Huppert, H.E., Sparks, R.S.J. and Turner, J.S., 1982. Effects of volatiles on mixing in calcalkaline magma systems. Nature, 297(5867): 554-557.

Huppert, H.E. and Woods, A.W., 2002. The role of volatiles in magma chamber dynamics. Nature, 420(6915): 493-495.

Jaupart, C. and Allègre, C.J., 1991. Gas content, eruption rate and instabilities of eruption regime in silicic volcanoes. Earth and Planetary Science Letters, 102(3-4): 413-429.

Jaupart, C. and Vergniolle, S., 1988. Laboratory models of Hawaiian and Strombolian eruptions. Nature, 331(6151): 58-60.

Jaupart, C. and Vergniolle, S., 1989. The generation and collapse of a foam layer at the roof of a basaltic magma chamber. Journal of Fluid Mechanics, 203: 347-380.

Jugo, P.J., 2009. Sulfur content at sulfide saturation in oxidized magmas. Geology, 37(5): 415418.

Kent, A.J.R., 2008. Melt Inclusions in Basaltic and Related Volcanic Rocks. Reviews in Mineralogy and Geochemistry, 69(1): 273-331.

Keppler, H., 1999. Experimental evidence for the source of excess sulfur in explosive volcanic eruptions. Science, 284(5420): 1652-1654. 
Kilbride, B.T.M., Mulina, K., Wadge, G., Johnson, R.W., Itikarai and Edmonds, M., 2018. Multiyear satellite observations of sulfur dioxide gas emissions and lava extrusion at Bagana volcano, Papua New Guinea. Frontiers in Earth Science.

Kiser, E., Palomeras, I., Levander, A., Zelt, C., Harder, S., Schmandt, B., Hansen, S., Creager, K. and Ulberg, C., 2016. Magma reservoirs from the upper crust to the Moho inferred from high-resolution Vp and Vs models beneath Mount St. Helens, Washington State, USA. Geology, 44(6): 411-414.

Koleszar, A.M., Saal, A.E., Hauri, E.H., Nagle, A.N., Liang, Y. and Kurz, M.D., 2009. The volatile contents of the Galapagos plume; evidence for $\mathrm{H} 2 \mathrm{O}$ and $\mathrm{F}$ open system behavior in melt inclusions. Earth and Planetary Science Letters, 287(3-4): 442-452.

Koyaguchi, T. and Kaneko, K., 1999. A two-stage thermal evolution model of magmas in continental crust. Journal of Petrology, 40(2): 241-254.

Kuritani, T., Yoshida, T., Kimura, J.-I., Hirahara, Y. and Takahashi, T., 2014. Water content of primitive low-K tholeiitic basalt magma from Iwate Volcano, NE Japan arc: implications for differentiation mechanism of frontal-arc basalt magmas. Mineralogy and Petrology, 108(1): 1-11.

Lange, R.A., Frey, H.M. and Hector, J., 2009. A thermodynamic model for the plagioclase-liquid hygrometer/thermometer. American Mineralogist, 94(4): 494-506.

Lavigne, F., Degeai, J.-P., Komorowski, J.-C., Guillet, S., Robert, V., Lahitte, P., Oppenheimer, C., Stoffel, M., Vidal, C.M. and Pratomo, I., 2013. Source of the great AD 1257 mystery eruption unveiled, Samalas volcano, Rinjani Volcanic Complex, Indonesia. Proceedings of the National Academy of Sciences, 110(42): 16742-16747.

Lejeune, A.M. and Richet, P., 1995. Rheology of crystal-bearing silicate melts: An experimental study at high viscosities. Journal of Geophysical Research: Solid Earth, 100(B3): 42154229.

Leonard, G., Cole, J., Nairn, I. and Self, S., 2002. Basalt triggering of the c. AD 1305 Kaharoa rhyolite eruption, Tarawera volcanic complex, New Zealand. Journal of Volcanology and Geothermal Research, 115(3): 461-486.

Liu, Y., Anderson, A.T., Wilson, C.J., Davis, A.M. and Steele, I.M., 2006. Mixing and differentiation in the Oruanui rhyolitic magma, Taupo, New Zealand: evidence from volatiles and trace elements in melt inclusions. Contr. Mineral. and Petrol., 151(1): 71-87.

Lloyd, A.S., Ferriss, E., Ruprecht, P., Hauri, E.H., Jicha, B.R. and Plank, T., 2016. An assessment of clinopyroxene as a recorder of magmatic water and magma ascent rate. Journal of Petrology, 57(10): 1865-1886.

Lloyd, A.S., Plank, T., Ruprecht, P., Hauri, E.H. and Rose, W., 2013. Volatile loss from melt inclusions in pyroclasts of differing sizes. Contr. Mineral. and Petrol., 165(1): 129-153.

Longo, A., Vassalli, M., Papale, P. and Barsanti, M., 2006. Numerical simulation of convection and mixing in magma chambers replenished with CO2-rich magma. Geophysical Research Letters, 33(21): L21305.

Longpré, M.-A., Stix, J., Klügel, A. and Shimizu, N., 2017. Mantle to surface degassing of carbon-and sulphur-rich alkaline magma at El Hierro, Canary Islands. Earth and Planetary Science Letters, 460: 268-280.

Lowenstern, J.B., 1994. Dissolved volatile concentrations in an ore-forming magma. Geology, 22(10): 893-896.

Lowenstern, J.B., 1995. Applications of silicate-melt inclusions to the study of magmatic volatiles. Magmas, fluids, and ore deposits, 23: 71-99.

Lowenstern, J.B., Bacon, C.R., Calk, L.C., Hervig, R.L. and Aines, R.D., 1994. Major-element, trace-element, and volatile concentrations in silicate melt inclusions from the tuff of Pine Grove, Wah Wah Mountains, Utah. 2331-1258, US Geological Survey.

Lowenstern, J.B., Mahood, G.A., Rivers, M.L. and Sutton, S.R., 1991. Evidence for extreme partitioning of copper into a magmatic vapor phase. Science, 252(5011): 1405-1409. 
Lowenstern, J.B. and Sinclair, W.D., 1996. Exsolved magmatic fluid and its role in the formation of comb-layered quartz at the Cretaceous Logtung W-Mo deposit, Yukon Territory, Canada. Transactions of the Royal Society of Edinburgh: Earth Sciences, 87: 303.

Lu, Y.-J., Loucks, R.R., Fiorentini, M.L., Yang, Z.-M. and Hou, Z.-Q., 2015. Fluid flux melting generated postcollisional high $\mathrm{Sr} / \mathrm{Y}$ copper ore-forming water-rich magmas in Tibet. Geology, 43(7): 583-586.

Luhr, J.F., Carmichael, I.S. and Varekamp, J.C., 1984. The 1982 eruptions of El Chichón Volcano, Chiapas, Mexico: mineralogy and petrology of the anhydritebearing pumices. Journal of Volcanology and Geothermal Research, 23(1-2): 69-108.

Maclennan, J., 2017. Bubble formation and decrepitation control the CO2 content of olivinehosted melt inclusions. Geochemistry, Geophysics, Geosystems, 18(2): 597-616.

Marsh, B., 1981. On the crystallinity, probability of occurrence, and rheology of lava and magma. Contr. Mineral. and Petrol., 78(1): 85-98.

Martin, V.M., Morgan, D.J., Jerram, D.A., Caddick, M.J., Prior, D.J. and Davidson, J.P., 2008. Bang! Month-scale eruption triggering at Santorini volcano. Science, 321(5893): 11781178 .

Mason, E., Edmonds, M. and Turchyn, A.V., 2017. Remobilization of crustal carbon may dominate volcanic arc emissions. Science, 357(6348): 290-294.

McCormick Kilbride, B., Edmonds, M. and Biggs, J., 2016. Observing eruptions of gas-rich compressible magmas from space. Nature Communications, 7.

Melekhova, E., Blundy, J., Martin, R., Arculus, R. and Pichavant, M., 2017. Petrological and experimental evidence for differentiation of water-rich magmas beneath St. Kitts, Lesser Antilles. Contr. Mineral. and Petrol., 172(11-12): 98.

Melnik, O. and Sparks, R., 1999. Nonlinear dynamics of lava dome extrusion. Nature, 402(6757): 37.

Melnik, O. and Sparks, R., 2002. Dynamics of magma ascent and lava extrusion at Soufrière Hills Volcano, Montserrat. Geological Society, London, Memoirs, 21(1): 153-171.

Menand, T. and Phillips, J.C., 2007. Gas segregation in dykes and sills. Journal of Volcanology and Geothermal Research, 159(4): 393-408.

Métrich, N., Bertagnini, A. and Di Muro, A., 2009. Conditions of magma storage, degassing and ascent at Stromboli: new insights into the volcano plumbing system with inferences on the eruptive dynamics. Journal of Petrology, 51(3): 603-626.

Metrich, N. and Clocchiatti, R., 1996. Sulfur abundance and its speciation in oxidized alkaline melts. Geochimica et Cosmochimica Acta, 60(21): 4151-4160.

Metrich, N., Clocchiatti, R., Mosbah, M. and Chaussidon, M., 1993. The 1989-1990 activity of Etna magma mingling and ascent of $\mathrm{H} 2 \mathrm{O} \quad \mathrm{Cl} \quad \mathrm{S}$ rich basaltic magma. Evidence from melt inclusions. Journal of volcanology and geothermal research, 59(1): 131-144.

Métrich, N. and Wallace, P.J., 2008. Volatile Abundances in Basaltic Magmas and Their Degassing Paths Tracked by Melt Inclusions. Reviews in Mineralogy and Geochemistry, 69(1): 363-402.

Moore, G. and Carmichael, I., 1998. The hydrous phase equilibria (to $3 \mathrm{kbar}$ ) of an andesite and basaltic andesite from western Mexico: constraints on water content and conditions of phenocryst growth. Contr. Mineral. and Petrol., 130(3-4): 304-319.

Moore, G., Vennemann, T. and Carmichael, I., 1998a. An empirical model for the solubility of $\mathrm{H} 2 \mathrm{O}$ in magmas to 3 kilobars. American Mineralogist, 83(1): 36-42.

Moore, G., Vennemann, T. and Carmichael, I.S.E., 1998b. An empirical model for the solubility of $\mathrm{H}<\mathrm{sub}>2</ \mathrm{sub}>\mathrm{O}$ in magmas to 3 kilobars. American Mineralogist, 83(1-2): 36-42.

Moore, L.R., Gazel, E., Tuohy, R., Lloyd, A.S., Esposito, R., Steele-MacInnis, M., Hauri, E.H., Wallace, P.J., Plank, T. and Bodnar, R.J., 2015. Special Collection: Glasses, Melts, and Fluids, as Tools for Understanding Volcanic Processes and Hazards. Bubbles matter: An 
assessment of the contribution of vapor bubbles to melt inclusion volatile budgets. American Mineralogist, 100(4): 806-823.

Moreno, H. and Gardeweg, M.C., 1989. La erupción reciente en el complejo volcánico Lonquimay (Diciembre 1988), Andes del Sur. Andean Geology, 16(1): 93-117.

Moretti, R., Papale, P. and Ottonello, G., 2003. A model for the saturation of COHS fluids in silicate melts. Geological Society, London, Special Publications, 213(1): 81-101.

Murphy, M., Sparks, R., Barclay, J., Carroll, M. and Brewer, T., 2000. Remobilization of andesite magma by intrusion of mafic magma at the Soufriere Hills Volcano, Montserrat, West Indies. Journal of petrology, 41(1): 21-42.

Neave, D.A., Passmore, E., Maclennan, J., Fitton, G. and Thordarson, T., 2013. Crystal-melt relationships and the record of deep mixing and crystallization in the ad 1783 Laki Eruption, Iceland. Journal of Petrology: egt027.

Neave, D.A. and Putirka, K.D., 2017. A new clinopyroxene-liquid barometer, and implications for magma storage pressures under Icelandic rift zones. American Mineralogist, 102(4): 777-794.

Newman, S. and Lowenstern, J.B., 2002. VolatileCalc: a silicate melt-H2O-CO2 solution model written in Visual Basic for excel. Computers \& Geosciences, 28(5): 597-604.

Oppenheimer, C., Scaillet, B. and Martin, R.S., 2011. Sulfur degassing from volcanoes: source conditions, surveillance, plume chemistry and earth system impacts. Reviews in mineralogy and geochemistry, 73(1): 363-421.

Oppenheimer, J., Rust, A., Cashman, K. and Sandnes, B., 2015. Gas migration regimes and outgassing in particle-rich suspensions. Front. Phys. 3: 60. doi: 10.3389/fphy.

Pallister, J.S., Hoblitt, R.P., Meeker, G.P., Knight, R.J. and Siems, D.F., 1996. Magma mixing at Mount Pinatubo: petrographic and chemical evidence from the 1991 deposits. Fire and mud: eruptions and lahars of Mount Pinatubo, Philippines: 687-731.

Pallister, J.S., Hoblitt, R.P. and Reyes, A.G., 1992. A basalt trigger for the 1991 eruptions of Pinatubo Volcano? Nature, 356(6368): 426.

Pan, V., Holloway, J.R. and Hervig, R.L., 1991. The pressure and temperature dependence of carbon dioxide solubility in tholeiitic basalt melts. Geochimica et Cosmochimica Acta, 55(6): 1587-1595.

Papale, P., 1999. Modeling of the solubility of a two-component $\mathrm{H}<\mathrm{sub}>2</$ sub $>\mathrm{O}+\mathrm{CO}$ $<$ sub $>2</$ sub $>$ fluid in silicate liquids. American Mineralogist, 84(4): 477-492.

Parmigiani, A., Faroughi, S., Huber, C., Bachmann, O. and Su, Y., 2016. Bubble accumulation and its role in the evolution of magma reservoirs in the upper crust. Nature, 532(7600): 492-495.

Parmigiani, A., Huber, C. and Bachmann, O., 2014. Mush microphysics and the reactivation of crystal-rich magma reservoirs. Journal of Geophysical Research: Solid Earth, 119(8): 6308-6322.

Phillips, J.C. and Woods, A.W., 2002. Suppression of large-scale magma mixing by melt-volatile separation. Earth and Planetary Science Letters, 204(1): 47-60.

Pistone, M., Caricchi, L., Ulmer, P., Burlini, L., Ardia, P., Reusser, E., Marone, F. and Arbaret, L., 2012. Deformation experiments of bubble-and crystal-bearing magmas: Rheological and microstructural analysis. Journal of Geophysical Research: Solid Earth, 117(B5).

Pistone, M., Caricchi, L., Ulmer, P., Reusser, E. and Ardia, P., 2013. Rheology of volatilebearing crystal mushes: mobilization vs. viscous death. Chemical Geology, 345: 16-39.

Plail, M., Barclay, J., Humphreys, M.C., Edmonds, M., Herd, R.A. and Christopher, T.E., 2014. Characterization of mafic enclaves in the erupted products of Soufrière Hills Volcano, Montserrat, 2009 to 2010. Geological Society, London, Memoirs, 39(1): 343-360.

Plail, M., Edmonds, M., Woods, A.W., Barclay, J., Humphreys, M.C., Herd, R.A. and Christopher, T., 2018. Mafic enclaves record syn-eruptive basalt intrusion and mixing. Earth and Planetary Science Letters, 484: 30-40. 
Plank, T., Kelley, K.A., Zimmer, M.M., Hauri, E.H. and Wallace, P.J., 2013. Why do mafic arc magmas contain $\sim 4 \mathrm{wt} \%$ water on average? Earth and Planetary Science Letters, 364: 168179.

Pritchard, M.E. and Gregg, P.M., 2016. Geophysical evidence for silicic crustal melt in the continents: where, what kind, and how much? Elements, 12(2): 121-127.

Prouteau, G. and Scaillet, B., 2003. Experimental constraints on the origin of the 1991 Pinatubo dacite. Journal of Petrology, 44(12): 2203-2241.

Ptacek, M., Edmonds, M. and Woods, A., 2018, sub judice. TBA. J. .

Putirka, K.D., 2005. Igneous thermometers and barometers based on plagioclase + liquid equilibria: Tests of some existing models and new calibrations. American Mineralogist, 90(2-3): 336-346.

Rae, A., Edmonds, M., Morgan, D.J., Kahl, M., Houghton, B.F. and Maclennan, J., 2016. Timescales of magma mixing prior to and during the 1959 Kilauea Iki eruption. Geology 44(6): 463-466.

Richards, J.P., 2011. High $\mathrm{Sr} / \mathrm{Y}$ arc magmas and porphyry $\mathrm{Cu} \pm \mathrm{Mo} \pm \mathrm{Au}$ deposits: just add water. Economic Geology, 106(7): 1075-1081.

Ripley, E.M. and Li, C., 2013. Sulfide saturation in mafic magmas: is external sulfur required for magmatic Ni-Cu-(PGE) ore genesis? Economic Geology, 108(1): 45-58.

Rivalta, E. and Segall, P., 2008. Magma compressibility and the missing source for some dike intrusions. Geophysical Research Letters, 35(4): L04306.

Roberge, J., Delgado-Granados, H. and Wallace, P.J., 2009. Mafic magma recharge supplies high $\mathrm{CO} 2$ and SO2 gas fluxes from Popocatépetl volcano, Mexico. Geology, 37(2): 107-110.

Robock, A., 2000. Volcanic eruptions and climate. Reviews of Geophysics, 38(2): 191-219.

Rocco, S., Woods, A.W., Harrington, J. and Norris, S., 2017. An experimental model of episodic gas release through fracture of fluid confined within a pressurized elastic reservoir. Geophysical Research Letters, 44(2): 751-759.

Roggensack, K., 2001. Unraveling the 1974 eruption of Fuego volcano (Guatemala) with small crystals and their young melt inclusions. Geology, 29(10): 911-914.

Roggensack, K., Williams, S.N., Schaefer, S.J. and Parnell Jr, R.A., 1996. Volatiles from the 1994 eruptions fo Rabaul: Understanding large caldera systems. Science, 273(5274): 490.

Rose-Koga, E.F., Koga, K.T., Hamada, M., Hélouis, T., Whitehouse, M.J. and Shimizu, N., 2014. Volatile ( $\mathrm{F}$ and $\mathrm{Cl}$ ) concentrations in Iwate olivine-hosted melt inclusions indicating lowtemperature subduction. Earth, Planets and Space, 66(1): 81.

Ruprecht, P. and Bachmann, O., 2010. Pre-eruptive reheating during magma mixing at Quizapu volcano and the implications for the explosiveness of silicic arc volcanoes. Geology, 38(10): 919-922.

Ruprecht, P., Bergantz, G.W., Cooper, K.M. and Hildreth, W., 2012. The crustal magma storage system of Volcán Quizapu, Chile, and the effects of magma mixing on magma diversity. Journal of Petrology: egs002.

Ruprecht, P., Bergantz, G.W. and Dufek, J., 2008. Modeling of gas-driven magmatic overturn: Tracking of phenocryst dispersal and gathering during magma mixing. Geochemistry, Geophysics, Geosystems, 9(7).

Ruth, D.C., Cottrell, E., Cortés, J.A., Kelley, K.A. and Calder, E.S., 2016. From passive degassing to violent strombolian eruption: the case of the 2008 eruption of Llaima volcano, Chile. Journal of Petrology, 57(9): 1833-1864.

Saar, M.O., Manga, M., Cashman, K.V. and Fremouw, S., 2001. Numerical models of the onset of yield strength in crystal-melt suspensions. Earth and Planetary Science Letters, 187(3): 367-379.

Saito, G., Kazahaya, K., Shinohara, H., Stimac, J. and Kawanabe, Y., 2001. Variation of volatile concentration in a magma system of Satsuma-Iwojima volcano deduced from melt inclusion analyses. Journal of Volcanology and Geothermal Research, 108(1-4): 11-31. 
Salazar, J.M., Hernández, P.A., Pérez, N.M., Melián, G., Álvarez, J., Segura, F. and Notsu, K., 2001. Diffuse emission of carbon dioxide from Cerro Negro volcano, Nicaragua, Central America. Geophysical Research Letters, 28(22): 4275-4278.

Scaillet, B., Clémente, B., Evans, B.W. and Pichavant, M., 1998. Redox control of sulfur degassing in silicic magmas. Journal of Geophysical Research: Solid Earth (1978-2012), 103(B10): 23937-23949.

Scaillet, B. and Pichavant, M., 2003. Experimental constraints on volatile abundances in arc magmas and their implications for degassing processes. Geological Society, London, Special Publications, 213(1): 23-52.

Scaillet, B. and Pichavant, M., 2005. A model of sulphur solubility for hydrous mafic melts: application to the determination of magmatic fluid compositions of Italian volcanoes. Annals of Geophysics.

Segall, P., 2013. Volcano deformation and eruption forecasting. Geological Society, London, Special Publications, 380(1): 85-106.

Shinohara, H., Kazahaya, K. and Lowenstern, J.B., 1995. Volatile transport in a convecting magma column: Implications for porphyry Mo mineralization. Geology, 23(12): 10911094.

Sides, I., Edmonds, M., Maclennan, J., Houghton, B., Swanson, D. and Steele-MacInnis, M., 2014a. Magma mixing and high fountaining during the 1959 Kîlauea Iki eruption, Hawai 'i. Earth and Planetary Science Letters, 400: 102-112.

Sides, I.R., Edmonds, M., Maclennan, J., Swanson, D.A. and Houghton, B.F., 2014b. Eruption style at Kîlauea Volcano in Hawai $i$ linked to primary melt composition Nature Geoscience, 7: 464-469.

Singer, B.S., Dungan, M.A. and Layne, G.D., 1995. Textures and Sr, Ba, Mg, Fe, K, and Ti compositional profiles in volcanic plagioclase: clues to the dynamics of calc-alkaline magma chambers. American Mineralogist, 80(7-8): 776-798.

Sisson, T. and Bacon, C., 1999. Gas-driven filter pressing in magmas. Geology, 27(7): 613-616.

Sisson, T. and Grove, T., 1993. Experimental investigations of the role of $\mathrm{H} 2 \mathrm{O}$ in calc-alkaline differentiation and subduction zone magmatism. Contr. Mineral. and Petrol., 113(2): 143166.

Sisson, T. and Layne, G., 1993. H2O in basalt and basaltic andesite glass inclusions from four subduction-related volcanoes. Earth and Planetary Science Letters, 117(3-4): 619-635.

Sparks, R., Huppert, H., Turner, J., Sakuyama, M. and O'Hara, M., 1984. The fluid dynamics of evolving magma chambers. Philosophical Transactions of the Royal Society of London A: Mathematical, Physical and Engineering Sciences, 310(1514): 511-534.

Sparks, R. and Marshall, L., 1986. Thermal and mechanical constraints on mixing between mafic and silicic magmas. Journal of Volcanology and Geothermal Research, 29(1-4): 99-124.

Sparks, S.R., Sigurdsson, H. and Wilson, L., 1977. Magma mixing: a mechanism for triggering acid explosive eruptions. Nature, 267(5609): 315-318.

Spilliaert, N., Allard, P., Métrich, N. and Sobolev, A., 2006. Melt inclusion record of the conditions of ascent, degassing, and extrusion of volatile-rich alkali basalt during the powerful 2002 flank eruption of Mount Etna (Italy). Journal of Geophysical Research: Solid Earth (1978-2012), 111(B4).

Steele-Macinnis, M., Esposito, R. and Bodnar, R.J., 2011. Thermodynamic model for the effect of post-entrapment crystallization on the $\mathrm{H} 2 \mathrm{O}-\mathrm{CO} 2$ systematics of vapor-saturated, silicate melt inclusions. Journal of Petrology, 52(12): 2461-2482.

Steiner, A.R., Browne, B.L. and Nye, C.J., 2012. Quenched mafic inclusions in $\leq 2200$ years BP deposits at Augustine Volcano, Alaska. International Geology Review, 54(11): 12411270 . 
Stolper, E. and Holloway, J.R., 1988. Experimental determination of the solubility of carbon dioxide in molten basalt at low pressure. Earth and Planetary Science Letters, 87(4): 397408.

Symonds, R.B., Rose, W.I., Bluth, G.J. and Gerlach, T.M., 1994. Volcanic-gas studies; methods, results, and applications. Reviews in Mineralogy and Geochemistry, 30(1): 1-66.

Tait, S., Jaupart, C. and Vergniolle, S., 1989. Pressure, gas content and eruption periodicity of a shallow, crystallising magma chamber. Earth and Planetary Science Letters, 92(1): 107123.

Tarasewicz, J., White, R.S., Woods, A.W., Brandsdóttir, B. and Gudmundsson, M.T., 2012. Magma mobilization by downward-propagating decompression of the Eyjafjallajökull volcanic plumbing system. Geophysical Research Letters, 39(19).

Tepley, F., Davidson, J. and Clynne, M., 1999. Magmatic interactions as recorded in plagioclase phenocrysts of Chaos Crags, Lassen Volcanic Center, California. Journal of Petrology, 40(5): 787-806.

Thomas, N., Tait, S. and Koyaguchi, T., 1993. Mixing of stratified liquids by the motion of gas bubbles: application to magma mixing. Earth and Planetary Science Letters, 115(1-4): 161-175.

Touloukian, Y.S., W. R. Judd and Roy, R.F., 1989. Physical Properties of Rocks and Minerals McGraw-Hill, New York., 11(2).

Ushioda, M., Takahashi, E., Hamada, M. and Suzuki, T., 2014. Water content in arc basaltic magma in the Northeast Japan and Izu arcs: an estimate from $\mathrm{Ca} / \mathrm{Na}$ partitioning between plagioclase and melt. Earth, Planets and Space, 66(1): 127.

Vergniolle, S. and Jaupart, C., 1986. Separated two-phase flow and basaltic eruptions. Journal of Geophysical Research: Solid Earth, 91(B12): 12842-12860.

Vidal, C.M., Métrich, N., Komorowski, J.-C., Pratomo, I., Michel, A., Kartadinata, N., Robert, V. and Lavigne, F., 2016. The 1257 Samalas eruption (Lombok, Indonesia): the single greatest stratospheric gas release of the Common Era. Scientific Reports, 6: 34868.

Viveiros, F., Cardellini, C., Ferreira, T., Caliro, S., Chiodini, G. and Silva, C., 2010. Soil CO2 emissions at Furnas volcano, São Miguel Island, Azores archipelago: Volcano monitoring perspectives, geomorphologic studies, and land use planning application. Journal of Geophysical Research: Solid Earth (1978-2012), 115(B12).

Voight, B., Widiwijayanti, C., Mattioli, G., Elsworth, D., Hidayat, D. and Strutt, M., 2010. Magma-sponge hypothesis and stratovolcanoes: Case for a compressible reservoir and quasi-steady deep influx at Soufrière Hills Volcano, Montserrat. Geophysical Research Letters, 37(19).

Wallace, P., 2001. Volcanic SO 2 emissions and the abundance and distribution of exsolved gas in magma bodies. Journal of Volcanology and Geothermal Research, 108(1): 85-106.

Wallace, P.J., 2005. Volatiles in subduction zone magmas: concentrations and fluxes based on melt inclusion and volcanic gas data. Journal of Volcanology and Geothermal Research, 140(1): 217-240.

Wallace, P.J., Anderson, A.T. and Davis, A.M., 1999. Gradients in H2O, CO2, and exsolved gas in a large-volume silicic magma system: Interpreting the record preserved in melt inclusions from the Bishop Tuff. Journal of Geophysical Research: Solid Earth, 104(B9): 20097-20122.

Wallace, P.J. and Edmonds, M., 2011. The sulfur budget in magmas: evidence from melt inclusions, submarine glasses, and volcanic gas emissions. Reviews in Mineralogy and Geochemistry, 73(1): 215-246.

Wallace, P.J. and Gerlach, T.M., 1994. Magmatic vapor source for sulfur dioxide released during volcanic eruptions: evidence from Mount Pinatubo. Science, 265(5171): 497-499. 
Wallace, P.J., Kamenetsky, V.S. and Cervantes, P., 2015. Melt inclusion CO2 contents, pressures of olivine crystallization, and the problem of shrinkage bubbles. American Mineralogist, 100(4): 787-794.

Waters, L.E. and Lange, R.A., 2015. An updated calibration of the plagioclase-liquid hygrometer-thermometer applicable to basalts through rhyolites. American Mineralogist, 100(10): 2172-2184.

Watts, R.B., de Silva, S.L., de Rios, G.J. and Croudace, I., 1999. Effusive eruption of viscous silicic magma triggered and driven by recharge: a case study of the Cerro Chascon-Runtu Jarita Dome Complex in Southwest Bolivia. Bull Volcanol, 61(4): 241-264.

Westrich, H. and Gerlach, T., 1992. Magmatic gas source for the stratospheric SO2 cloud from the June 15, 1991, eruption of Mount Pinatubo. Geology, 20(10): 867-870.

Williams-Jones, A.E. and Heinrich, C.A., 2005. 100th Anniversary special paper: vapor transport of metals and the formation of magmatic-hydrothermal ore deposits. Economic Geology, 100(7): 1287-1312.

Witham, F., Blundy, J., Kohn, S.C., Lesne, P., Dixon, J., Churakov, S.V. and Botcharnikov, R., 2012. SolEx: A model for mixed COHSCl-volatile solubilities and exsolved gas compositions in basalt. Computers \& Geosciences, 45: 87-97.

Woods, A.W. and Cardoso, S.S., 1997. Triggering basaltic volcanic eruptions by bubble-melt separation. Nature, 385(6616): 518.

Woods, A.W. and Cowan, A., 2009. Magma mixing triggered during volcanic eruptions. Earth and Planetary Science Letters, 288(1): 132-137.

Woods, A.W. and Huppert, H.E., 2003. On magma chamber evolution during slow effusive eruptions. Journal of Geophysical Research: Solid Earth, 108(B8).

Woods, A.W. and Koyaguchi, T., 1994. Transitions between explosive and effusive eruptions of silicic magmas. Nature, 370(6491): 641-644.

Wright, T.L. and Fiske, R.S., 1971. Origin of the differentiated and hybrid lavas of Kilauea volcano, Hawaii. Journal of Petrology, 12(1): 1-65.

Zajacz, Z., Candela, P.A., Piccoli, P.M. and Sanchez-Valle, C., 2012. The partitioning of sulfur and chlorine between andesite melts and magmatic volatiles and the exchange coefficients of major cations. Geochimica et Cosmochimica Acta, 89: 81-101.

Zajacz, Z. and Halter, W., 2009. Copper transport by high temperature, sulfur-rich magmatic vapor: Evidence from silicate melt and vapor inclusions in a basaltic andesite from the Villarrica volcano (Chile). Earth and Planetary Science Letters, 282(1): 115-121.

\section{Figure captions}

Figure 1: Schematic diagram to illustrate how magmas may achieve volatile-saturation. A: decompressing silicate melt achieves saturation in an exsolved volatile phase, which promotes degassing-induced crystallisation. B: Isobaric crystallisation in a crustal magma reservoir causes second boiling and development of an exsolved volatile phase. MVP: (exsolved) magmatic volatile phase.

Figure 2: Solubility model for rhyolite (Newman and Lowenstern, 2002), showing melt $\mathrm{CO}_{2}$ concentration versus melt water concentration. Isobars are in black solid lines, and represent the 
1520

1521

1522

1523

1524

1525

1526

1527

1528

1529

1530

1531

1532

1533

1534

1535

1536

1537

1538

1539

1540

1541

1542

1543

1544

1545

1546

1547

1548

1549

1550

1551

1552

1553

locus of values for dissolved $\mathrm{H}_{2} \mathrm{O}$ and $\mathrm{CO}_{2}$ in rhyolitic melt in equilibrium with $\mathrm{H}_{2} \mathrm{O}-\mathrm{CO}_{2}$ vapor at $800 \mathrm{C}$ and selected pressures (labelled, in $\mathrm{MPa}$ ). Isopleths are dashed lines, and represent the locus of rhyolitic melt compositions in equilibrium with the given exsolved volatile phase compositions: $20 \mathrm{~mol} \% \mathrm{H}_{2} \mathrm{O}\left(80 \mathrm{~mol} \% \mathrm{CO}_{2}\right), 50 \mathrm{~mol} \% \mathrm{H}_{2} \mathrm{O}$ and $\mathrm{CO}_{2}$; and $80 \mathrm{~mol} \% \mathrm{H}_{2} \mathrm{O}(20$ $\mathrm{mol} \% \mathrm{CO}_{2}$ ) at $800 \mathrm{C}$. The orange and red dots show the behaviour of vapour-undersaturated and vapor-saturated melts (respectively) with (top orange dot) and without (bottom orange dot) $\mathrm{CO}_{2}$. These examples are discussed in the text.

Figure 3: Evolution of melt $\mathrm{H}_{2} \mathrm{O}$ content (red, in wt\%) and total fraction of exsolved water (blue, in $\mathrm{wt} \%$ ) during crystallization from basalt to rhyolite, at $200 \mathrm{MPa}$, illustrating how substantial fractions of exsolved volatiles may be generated during isobaric crystallization. Curves are labelled with the initial basalt melt $\mathrm{H}_{2} \mathrm{O}$ content, in wt $\%$. If the evolved liquids and exsolved volatiles are segregated from their crystalline products, the fraction of exsolved volatiles in the magma (melt) is much higher than shown. For magma crystallization at lower and higher pressures, fractions of exsolved volatiles reach higher and lower values respectively (due to the lower and higher solubilities of water, respectively). Calculations are made using RhyoliteMelts (Ghiorso and Gualda, 2015).

Figure 4: Melt inclusion $\mathrm{CO}_{2}$ and $\mathrm{H}_{2} \mathrm{O}$ concentrations; and isobars to show volatile concentrations in equilibrium with an exsolved volatile phase for different pressures (marked). A: Volatile data for basaltic melt inclusions, hosted by olivine. Isobars are appropriate for Canary Island basalt (Burgisser et al., 2015). Data are shown for Fernandina and Santiago from (Koleszar et al., 2009); for Kîlauea from (Sides et al., 2014b), for El Hierro from (Longpré et al., 2017) for Laki (Hartley et al., 2014), for Holuhraun (Bali et al., 2018), for Stromboli (Métrich et al., 2009), for Etna (Spilliaert et al., 2006) for Llaima (De Maisonneuve et al., 2012; Ruth et al., 2016) and for Fuego (Berlo et al., 2012; Lloyd et al., 2016; Roggensack, 2001; Sisson and Layne, 1993). B: Data for dacitic and rhyolitic melt inclusions, hosted by plagioclase and quartz. Isobars appropriate for rhyolite (Newman and Lowenstern, 2002). Data are shown for Pine Grove (Lowenstern et al., 1994), Soufrière Hills (Edmonds et al., 2014b), Bishop Tuff (Wallace et al., 1999), Oruanui, Taupo (Liu et al., 2006), Rabaul (Roggensack et al., 1996), Popocatepetl (Atlas et al., 2006) and Satsuma-Iwojima (Saito et al., 2001).

Figure 5. The effects of an exsolved volatile phase on magma compressibility and how it may evolve during magma fractionation in a magma reservoir. A) Effective compressibility of a melt- 
1554 volatile mixture (with no crystals) in the case that there is 2, 4 and $6 \mathrm{wt} \% \mathrm{H}_{2} \mathrm{O}$ in the melt at 1200 1555 K. B) The dependence of the compressibility of a melt-crystal-volatile mixture on the crystal 1556 content of the melt. As the magma cools and crystallises, the melt becomes volatile-saturated and 1557 the compressibility rapidly increases beyond that for the solid rock. Curves are shown for melt 1558 with a $\mathrm{H}_{2} \mathrm{O}$ content of 3,4 and $6 \mathrm{wt} \%$, in a reservoir of depth $5 \mathrm{~km}$, with magma temperature 1559 varying with the crystal content of the melt. C) Rate of change of the reservoir pressure during 1560 second boiling as a function of the change in temperature, normalised to the critical pressure 1561 required to trigger an eruption, here taken to be $10 \mathrm{MPa}$ (Blake, 1984). Curves are shown for $\mathrm{H}_{2} \mathrm{O}$ 1562 contents of 3,4 and $6 \mathrm{wt} \%$.

1564 Figure 6. Data on the cumulative mass erupted from (A) Soufriere St Vincent and (B) Paracutin, 1565 as a function of time, compared to the exponential model for the gradual waning of the eruption 1566 rate; (C) Lanquimay, compared to a model for the mass erupted from a two magma chamber 1567 system, with the dashed line illustrating the erupted mass from the deeper chamber into the upper 1568 chamber, and the black line the erupted mass from the upper chamber to the surface. The lower 1569 chamber only starts to supply a significant flux of magma once the upper chamber has 1570 decompressed. (D) May St Helens, after May 181980 until 1985. Here the symbols represent the 1571 incremental erupted volume during successive dome explosion events; the black line is a model 1572 with an idealized steadily waning eruption rate and the dashed line is the model in which each 1573 explosive event occurs once a prescribed overpressure has been reached (for details see 1574 (Berkowitz and Woods, 2018 under review)).

Figure 7: Illustration of the process of overturn associated with volatile exsolution from a melt prior to an eruption. A: the lower layer of melt is deep and viscous, leading to a dominant plume of bubble-rich buoyant melt rising up through the overlying volatile poor melt, leading to large scale overturn. B: the lower layer is less viscous and shallower, leading to smaller plumes of bubble-laden buoyant melt rising up into the overlying layer of volatile-poor melt. These plumes become unstable and are mixed into the overlying layer of melt rather than leading to a dominant overturn event (Woods and Cowan, 2009). The vertical scale of the experiments is $\sim 20 \mathrm{~cm}$.

Figure 8. Overturn during an eruption, as the lower layer of volatile-rich melt expands and becomes less dense than the original upper layer. This leads to a change in the erupting melt issuing from the summit 'vent' and the flank 'vent' following the overturn (Experiment courtesy of Alex Cowan). The vertical scale of the experimental tank is $\sim 20 \mathrm{~cm}$. 
1589 Figure 9: Results of experiments to show the exsolution of gas in a particle-laden viscous 1590 polymer solution as the solution is decompressed. Top: sequence of images showing the solution 1591 during and after decompression from 1 Bar to $35 \mathrm{mBar}$, leading to (i) exsolution of gas, (ii) liquid 1592 displacement within the pack and some dilation of the porous pack, producing an increase in 1593 permeability of the pack, (iii) the development of channelised permeable flow of gas from the 1594 pack; (iv) gradual relaxation of the depth of the porous layer once the connected gas phase has 1595 been driven out of the system. The tank is $18.2 \mathrm{~cm}$ wide. Owing to presence of residual gas, and 1596 the original expulsion of some liquid from the pack, a thin layer of melt may be seen above the 1597 porous pack (light layer at top of pack). Bottom: Graph illustrating the height of the particle-laden 1598 solution as a function of time when the pack is subjected to a decompression to different final 1599 pressures, as shown in the legend. With high final pressure, the effect is a monotonic increase in 1600 depth, as there is less gas exsolved. With a low final pressure the effect is a much larger increase 1601 in depth during the initial exsolution, but then the pack relaxes as gas is able to escape from the 1602 system. After Ptacek et al., sub judice (2018).

1604 Figure 10: Cartoon diagram to summarise the generation, transport and accumulation 1605 mechanisms of the exsolved volatile phase, and the ways in which the exsolved volatile phase 1606 plays a role in driving magma mingling and mixing involving underplating mafic magmas. 
A: Exsolution of volatiles during decompression, "first boiling"

Melt water content, wt $\%$

Pressure
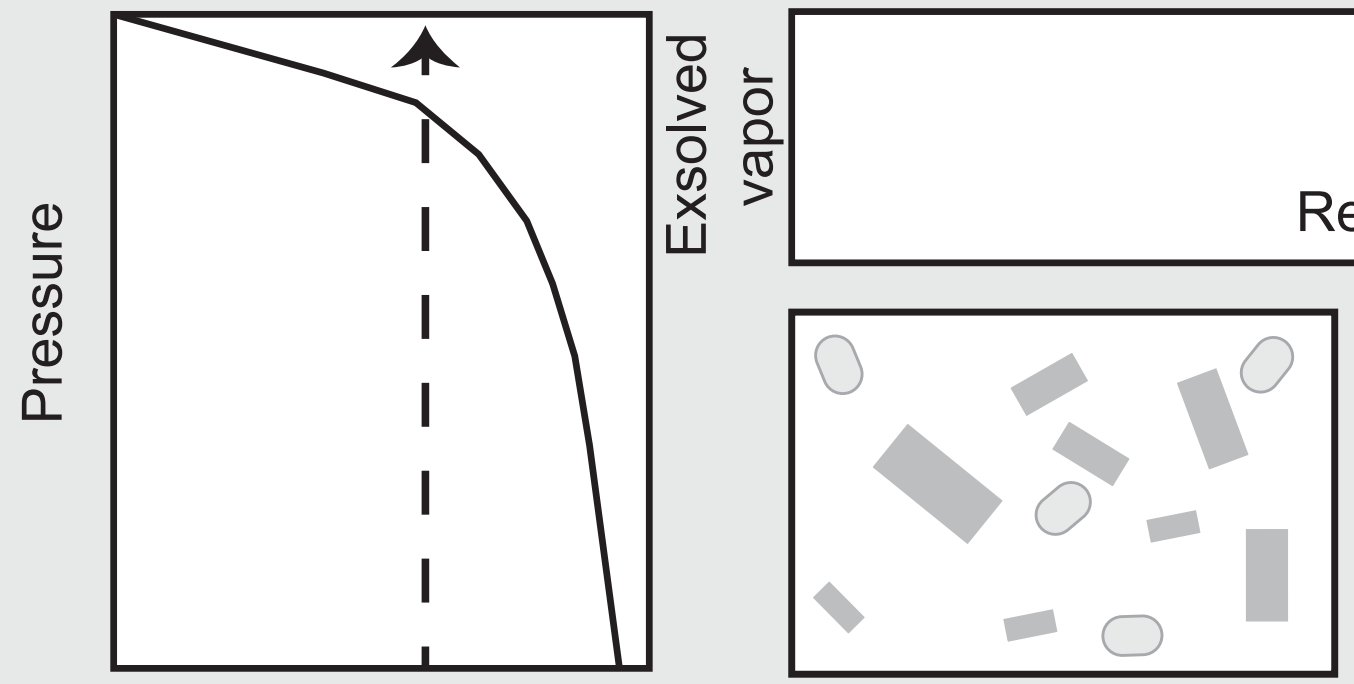

Reservoir

Near-surface

-

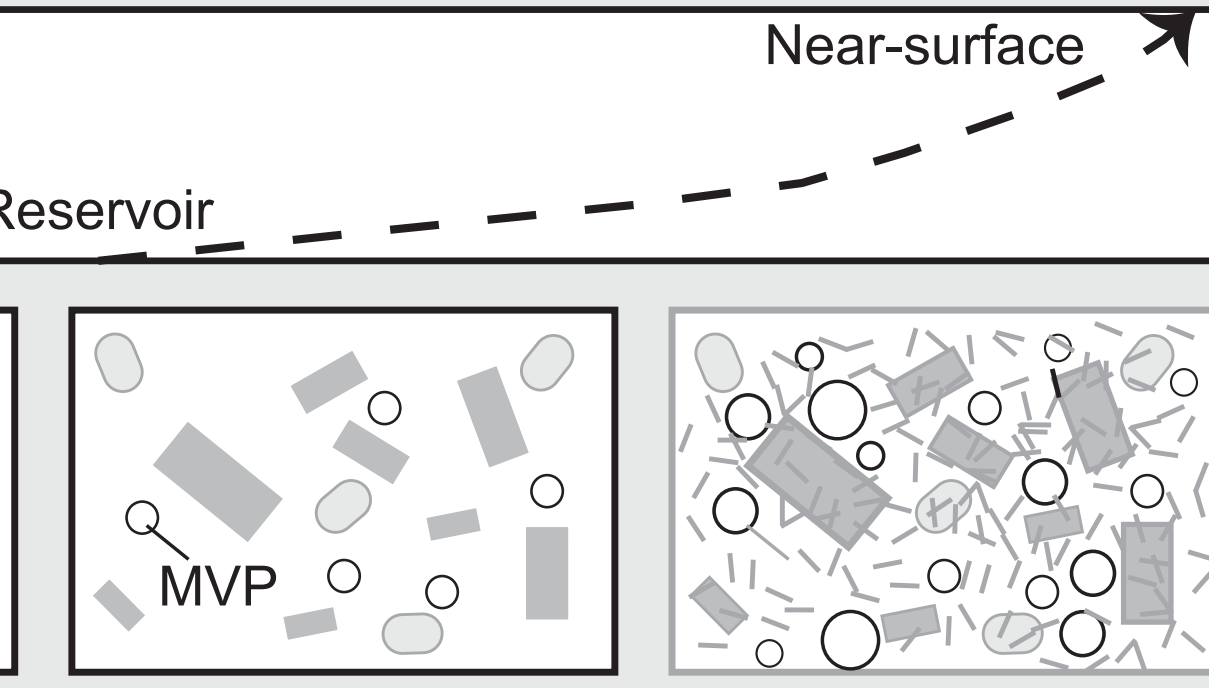

B: Exsolution of volatiles during cooling and crystallisation, "second boiling"

Melt water content, wt $\%$

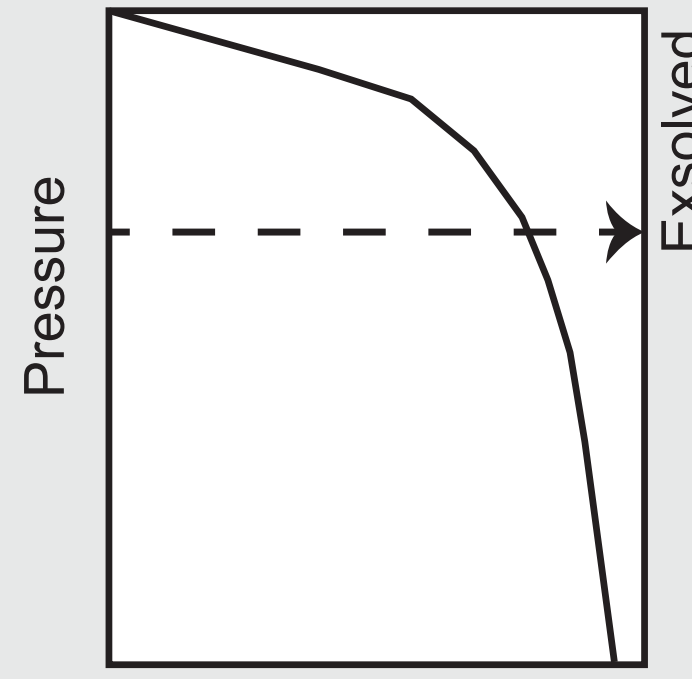

Crystal content, vol\%

Crystal content, vol\%
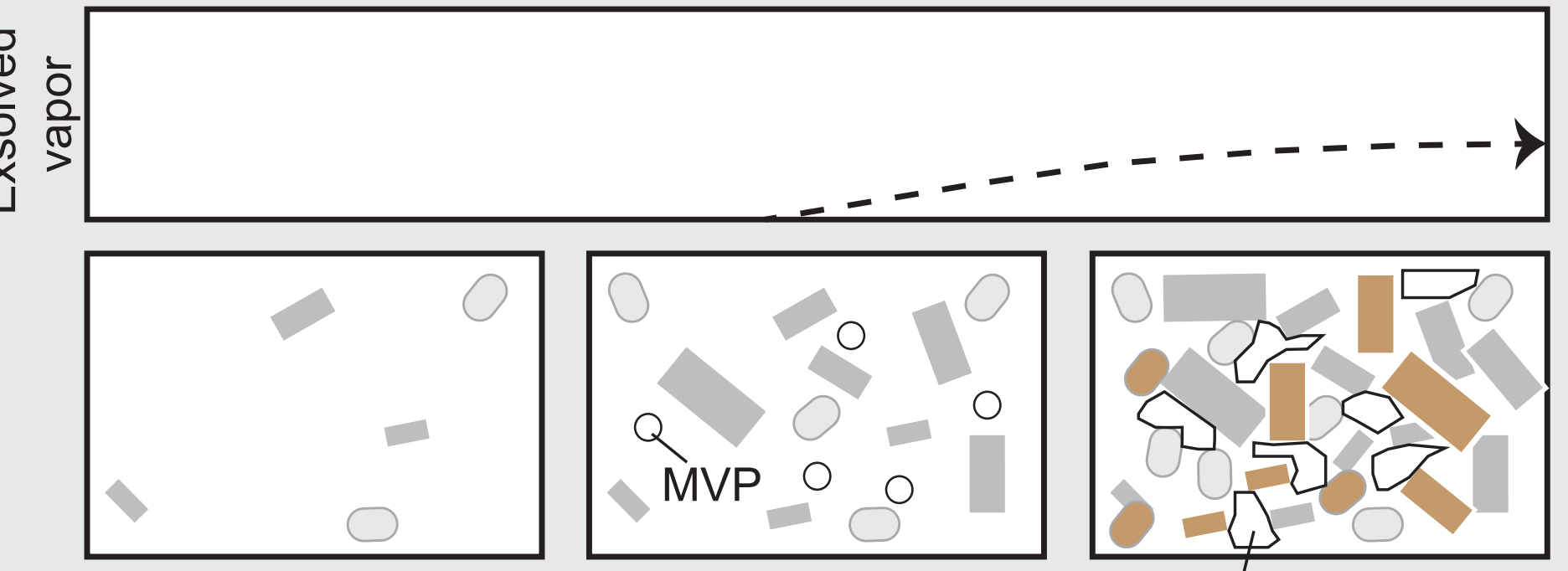

MVP 


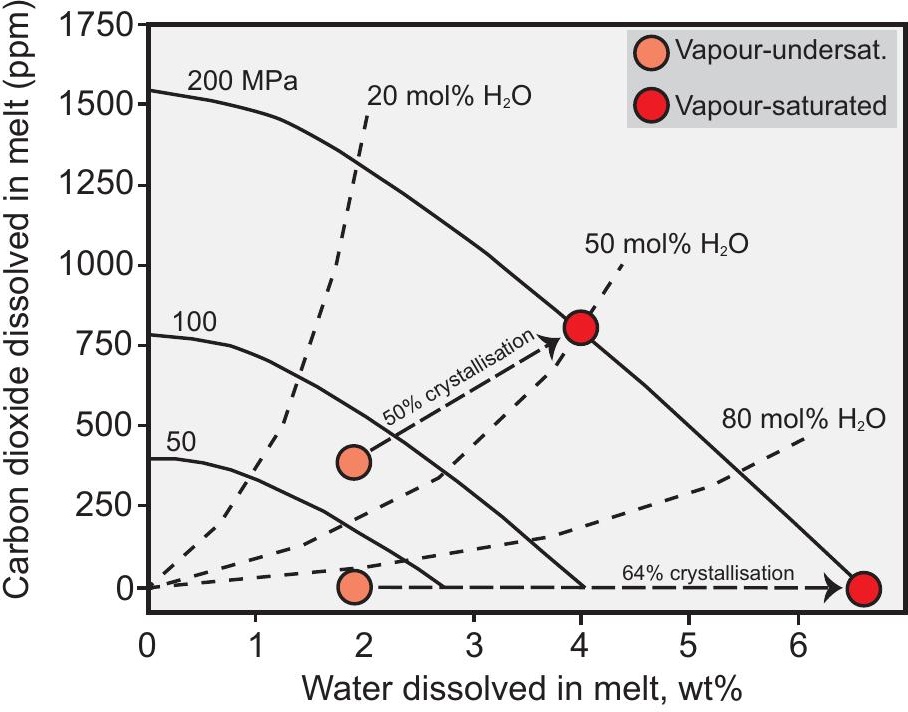




\section{Rhyolite}

$\mathrm{SiO}_{2}$ content, wt $\%$

Basalt

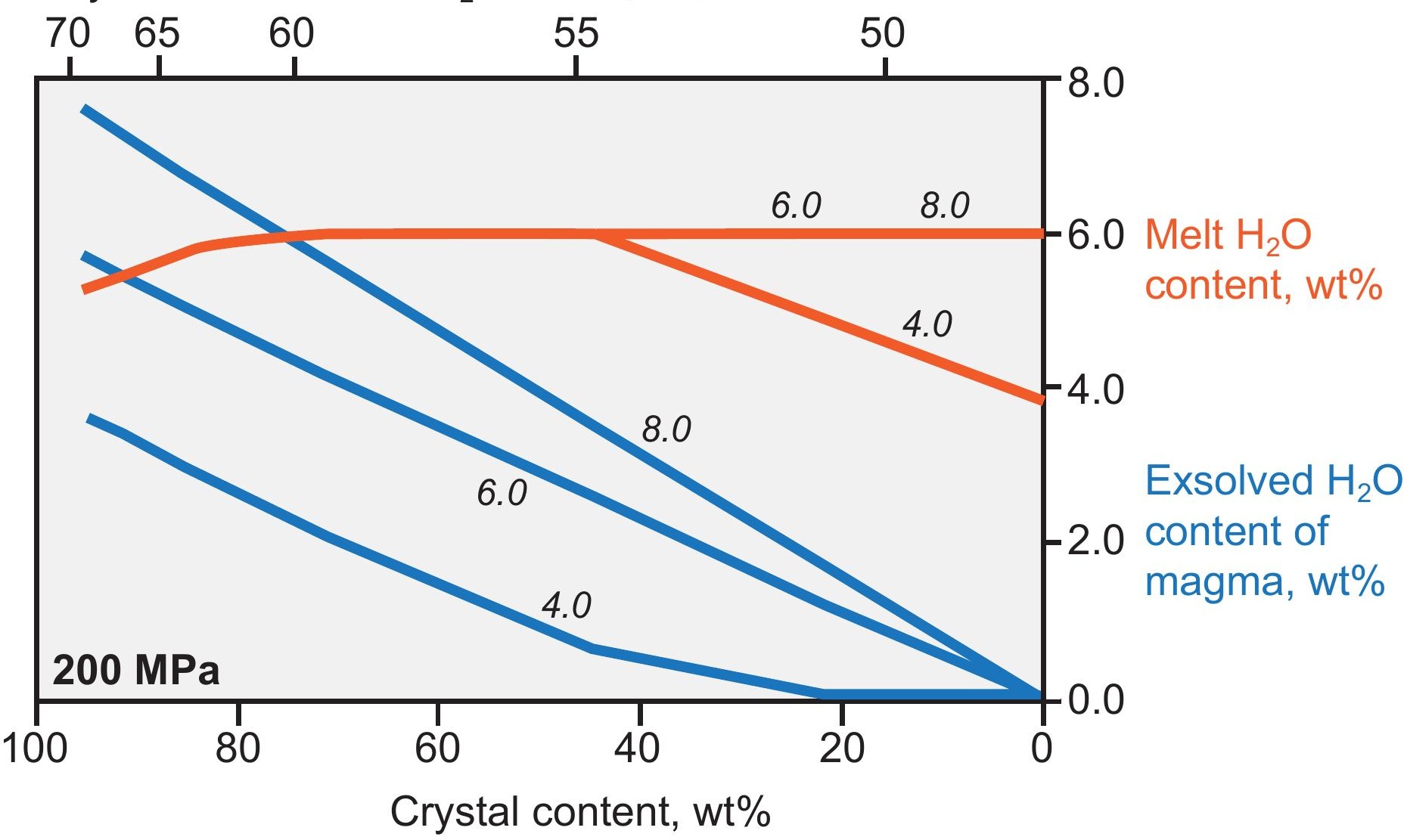



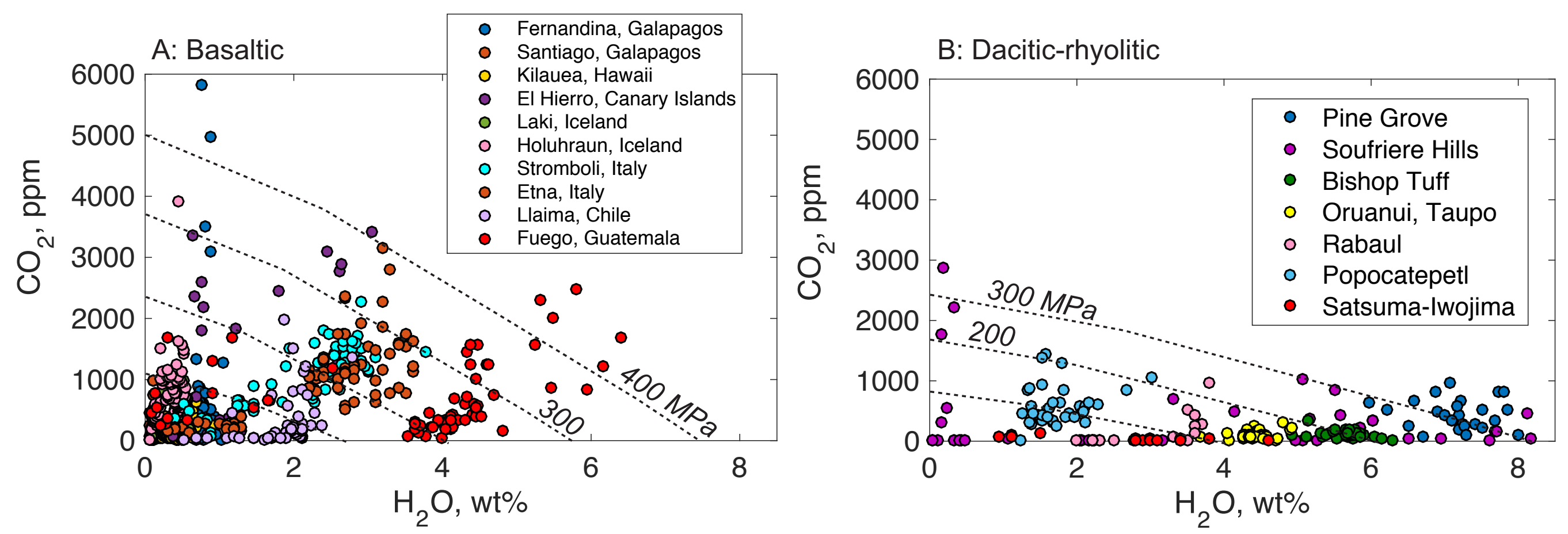

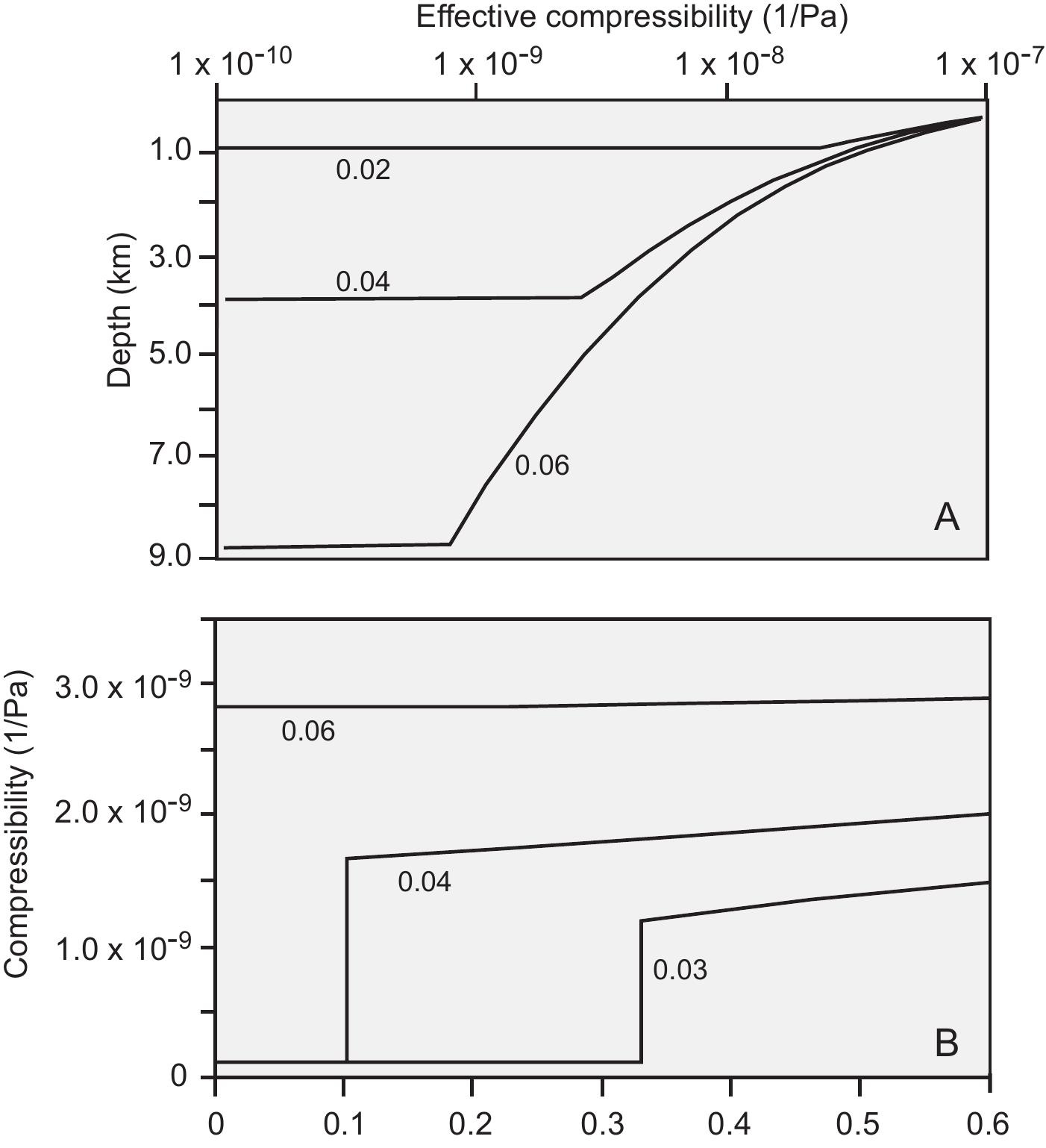

Crystal content (vol\%)

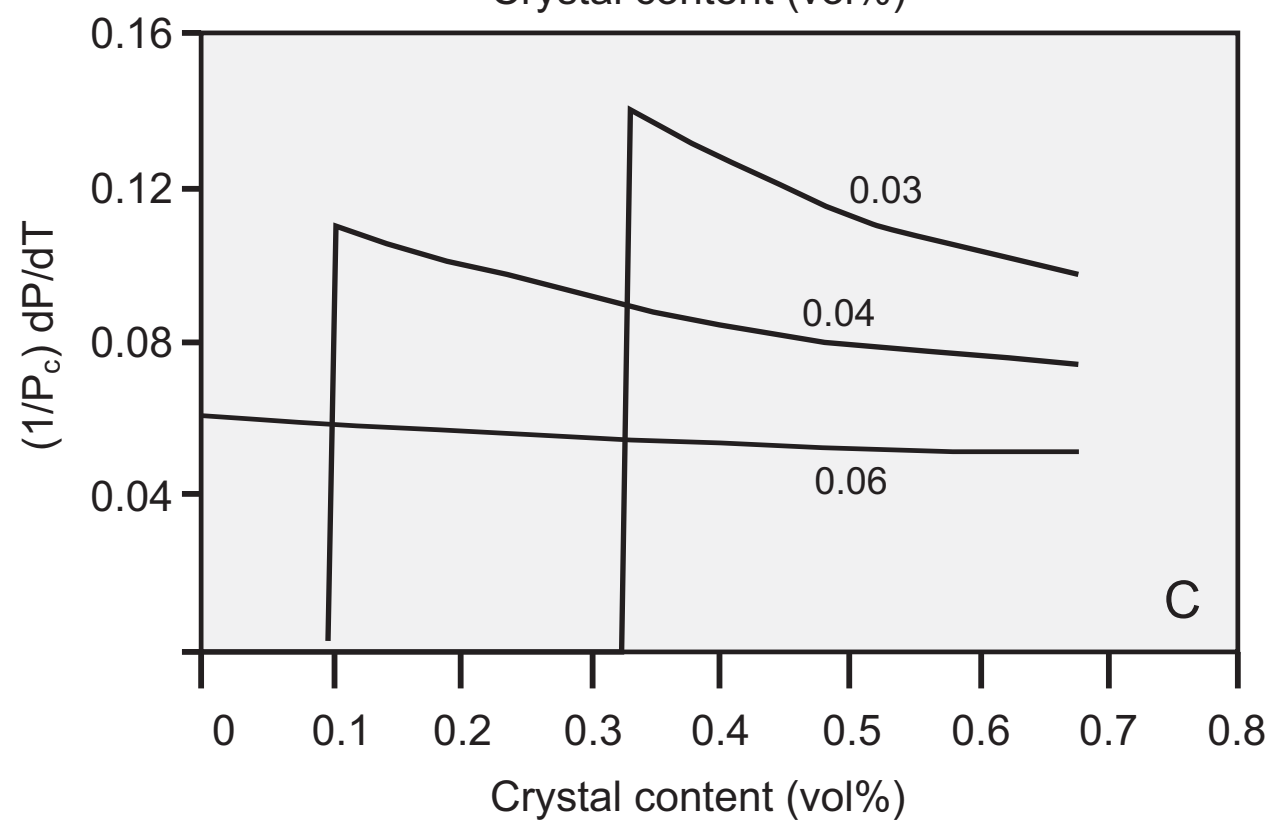



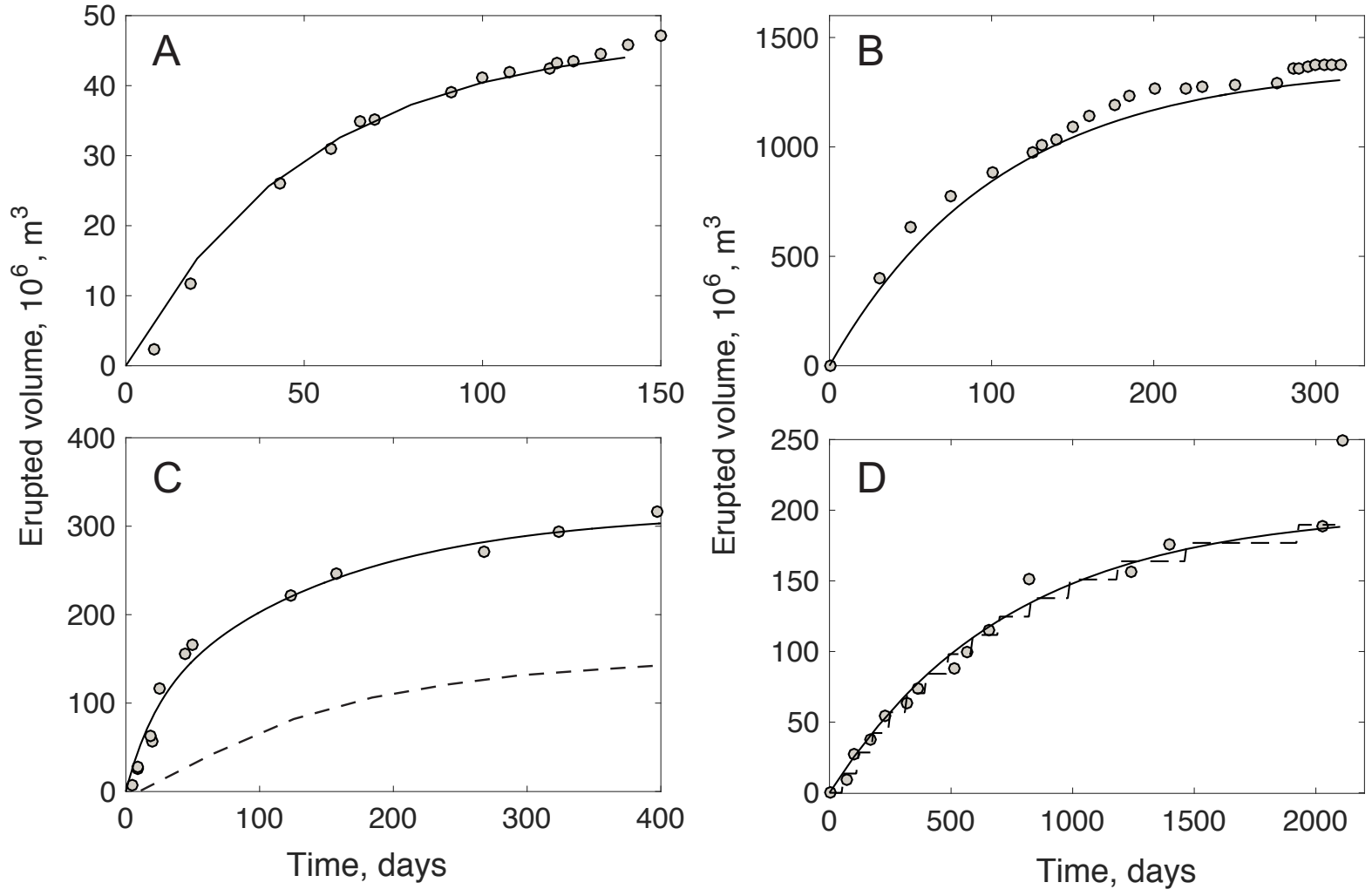


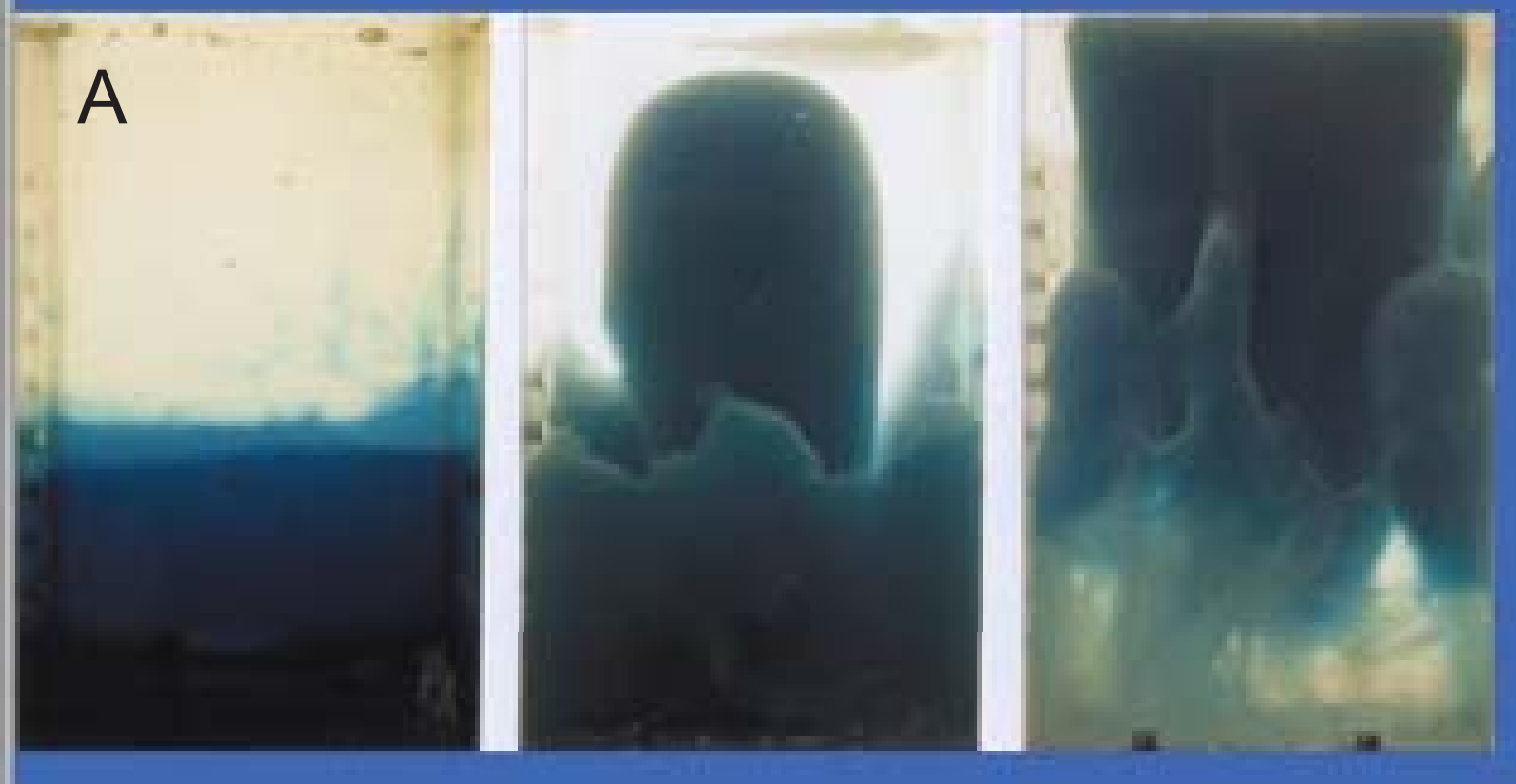

\section{B}
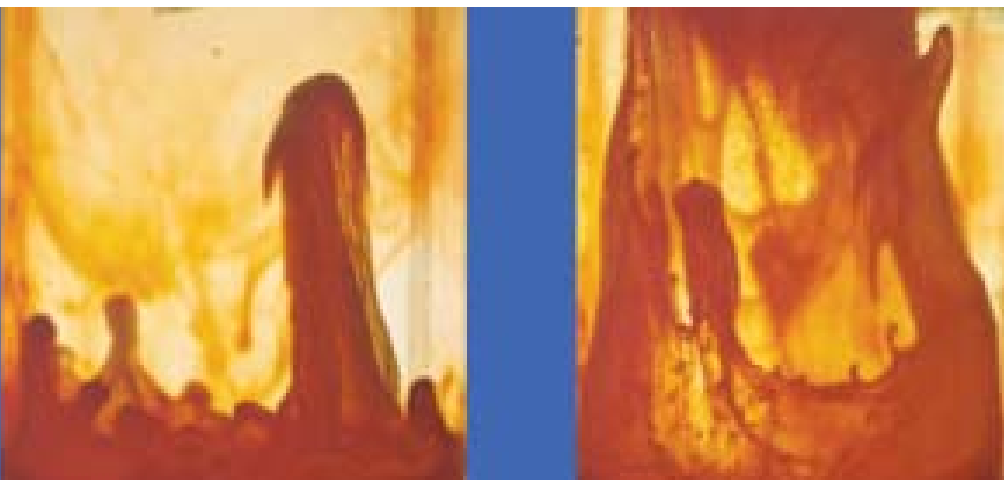


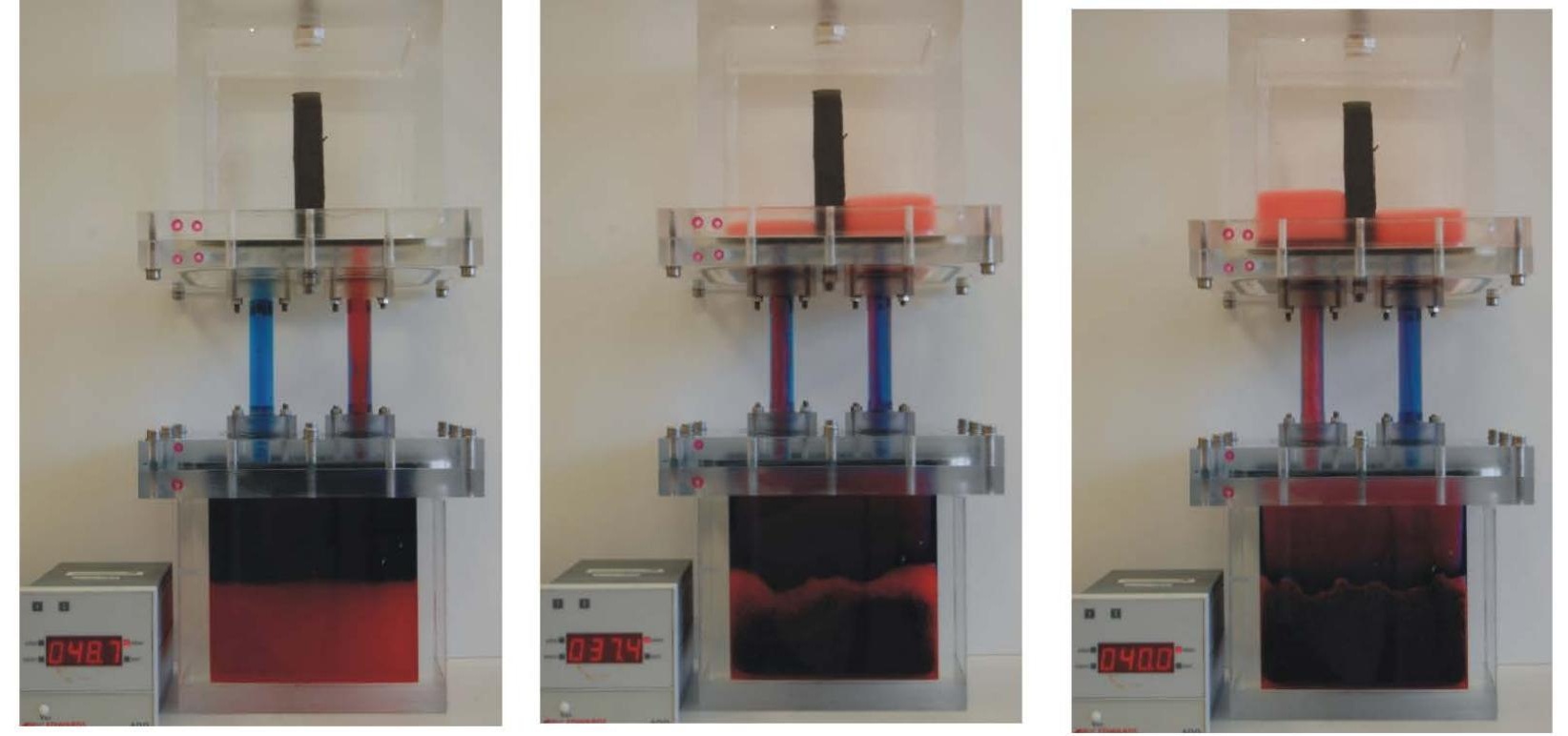




\section{$\mathrm{P}=1 \mathrm{Bar}$}

$\mathrm{t}=0 \mathrm{~s}$

$\mathrm{P}=35 \mathrm{mBar}$

$P=35 \mathrm{mBar}$ $\mathrm{t}=60 \mathrm{~s}$
$P=35 \mathrm{mBar}$

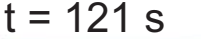

$P=35 \mathrm{mBar}$
$P=35 \mathrm{mBar} \quad \mathrm{P}=35 \mathrm{mBar}$

\section{$\mathrm{t}=1854 \mathrm{~s}$} $t=360 \mathrm{~s}$

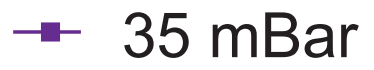

$\rightarrow-42$

$\rightarrow 50$

$-70$

$\rightarrow 110$

0.60

$\begin{array}{lllllll}0 & 1000 & 2000 & 3000 & 4000 & 5000 & 6000\end{array}$ Experimental time (seconds) 
